\title{
Laser Machining by short and ultrashort pulses, state of the art and new opportunities in the age of the photons
}

\author{
J. Meijer ${ }^{1}$ (coordinator), K. Du², A. Gillner ${ }^{3}$, D. Hoffmann ${ }^{3}$, V.S. Kovalenko ${ }^{4}$, T. Masuzawa ${ }^{5}$, A. Ostendorf ${ }^{6}$, \\ R. Poprawe ${ }^{3}$, W. Schulz ${ }^{3}$. \\ ${ }^{1}$ University of Twente, Enschede, Netherlands \\ ${ }^{2}$ EdgeWave $\mathrm{GmbH}$, Aachen, Germany. \\ ${ }^{3}$ Fraunhofer Institut für Lasertechnik ILT, Aachen, Germany. \\ ${ }^{4}$ National University of Ukraine, Kiev. \\ ${ }^{5}$ University of Tokyo Japan. \\ ${ }^{6}$ Laser Zentrum Hannover, Germany.
}

\begin{abstract}
An overview is given of the applications of short and ultrashort lasers in material processing. Shorter pulses reduce heat-affected damage of the material and opens new ways for nanometer accuracy. Even forty years after the development of the laser there is a lot of effort in developing new and better performing lasers. The driving force is higher accuracy at reasonable cost, which is realised by compact systems delivering short laser pulses of high beam quality. Another trend is the shift towards shorter wavelengths, which are better absorbed by the material and which allows smaller feature sizes to be produced. Examples of new products, which became possible by this technique, are given. The trends in miniaturization as predicted by Moore and Taniguchi are expected to continue over the next decade too thanks to short and ultrashort laser machining techniques. After the age of steam and the age of electricity we have entered the age of photons now.
\end{abstract}

Keywords: Micro-machining, Laser, Ablation.

\section{INTRODUCTION}

Photons are in this century. They are replacing electrons as the favorite tool in modern industry. Light is used for everything from eye surgery to telephone technology and materials processing.

An important property of light is that it has no volume, photons have no charge, so when concentrated into a very small space, they don't repulse each other like negatively charged electrons do. This is a very important property for ultrashort machining.

In the fifth century B.C. the philosopher Empedocles had the brilliant intuition that light is a streaming substance emitted by the sun and that we are not conscious of its movement because it moves too fast [1]. Now we know that light is produced by changes in the energy level of electrons. It moves through space as a wave, but when it encounters matter it behaves like a particle of energy, a photon. Not all photons have the same amount of energy. The visible part of the spectrum contains wavelengths from 400 to $750 \mathrm{~nm}$. Radiation below $400 \mathrm{~nm}$ includes the harmful frequencies of UV and x-rays, while above $750 \mathrm{~nm}$ the invisible infrared, microwave and radio frequencies are included.

The energy of photons is $E=h v$. For the visible $500 \mathrm{~nm}$ wavelength this is $4.10^{-19} \mathrm{~J}$ or $2.5 \mathrm{eV}$ per photon, which is not enough to break the chemical bonds in the material. This requires 3 to $10 \mathrm{eV}$. In the laser materials processing this can be overcome in different ways. The first solution is simply heating the material by absorption of laser energy, which is a thermal or pyrolitic process. Secondly higher energy photons (UV) can be used with photon energies of 3 to $7 \mathrm{eV}$, which is used directly to break the chemical bonds (especially plastics). This is a photolitic process. For metals even more energy is required (up to 5 times the sublimation energy of about 4 $\mathrm{eV}$ for most metals). The third option is using lasers that deliver so many photons on a time that electrons are hit by several photons simultaneously. Absorption of multi photons has the same result as single high energetic photons. Pulses delivered by pico- and femto second lasers can strip up to 5 electrons of a molecule removing solid material as highly ionised plasma. In this case the photon energy, thus the wavelength, is less important because energy is transferred by multi photons simultaneously. This is a reason that such lasers are preferable operated in the visible part of the spectrum with relatively simple optics. Although the femtosecond lasers are still looking for applications, the race for shorter wavelengths continuous. Recently the first isolated attosecond $\left(10^{-18} \mathrm{~s}\right)$ pulses have been produced [2] and measured [3] in the extreme ultraviolet around 14 $\mathrm{nm}$ wavelength. They are produced by high harmonic generation, which requires intense femto second lasers in turn. In this paper an overview is given of short and ultrashort pulsed lasers, the fields of applications and further developments.

2 LASER-MATERIAL INTERACTIONS, WHAT IS SHORT, WHAT IS ULTRASHORT?

In laser machining processes we distinguish pyrolitic and photolitic processes. In pyrolitic processes the laser energy is absorbed by heating the material, resulting in a temperature rise, melting or evaporation of the material while photolitic processes result in photon induced chemical reactions. This paper addresses mainly pyrolitic processes.

\subsection{Short/ultrashort}

Since the invention of the laser there has been a constant development to shorter pulse times. Only a few years ago 10 nanosecond pulses were the shortest obtainable but now femtosecond lasers are applied and even shorter pulses can be obtained in the lab. Therefore we will discuss first what is short from the viewpoint of the laser.

Like very long distances can be expressed in light-years we can express very short times in light-distances, that is the distance a light wave or a photon travels during that short time. This distance amounts for 100 fs pulse only $30 \mu \mathrm{m}$. In Figure 2.1 these light-distances are shown in relation to the laser machining processes. For very short fs pulses this distance is in the order of the wavelength of the light! 


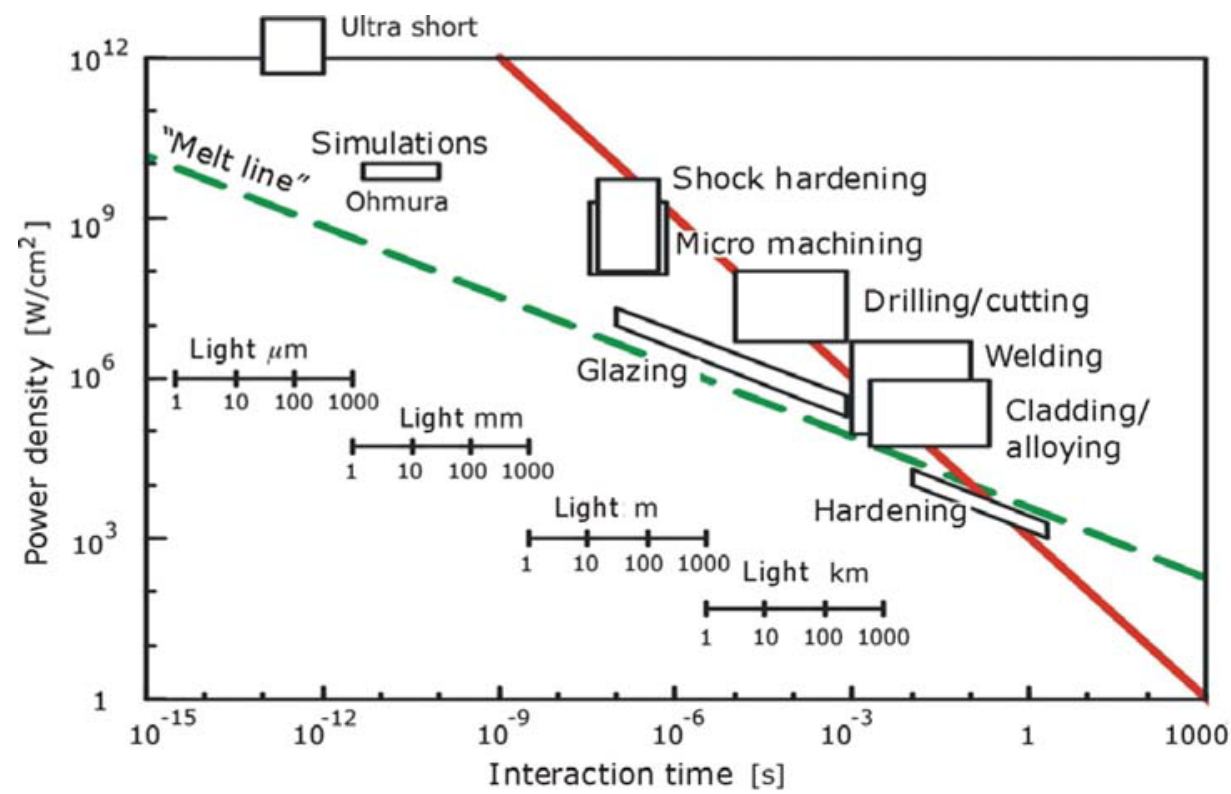

Figure 2.1. Overview of laser machining processes. The 'conventional' laser processes are found around the line of $1 \mathrm{~kJ} / \mathrm{cm}^{2}$. The dotted line indicates the melt boundary of metal. Ultrashort processes require less energy per $\mathrm{cm}^{2}$ in general.

The question how short is short enough can also be approached from the viewpoint of the applications. Chen [4] compared 3 lasers with different pulse width (Table 2.1) and concluded that shorter pulses produce better quality but at higher cost.

Table 2.1. General comparison of lasers with different pulse width and their performance and cost

\begin{tabular}{llll}
\hline Laser type & $\begin{array}{l}\text { Free } \\
\text { running } \\
\text { Nd:YAG }\end{array}$ & $\begin{array}{l}\text { Q- } \\
\text { switched } \\
\text { Nd:YAG }\end{array}$ & $\begin{array}{l}\text { CPA Ti: } \\
\text { sapphire }\end{array}$ \\
\hline Pulse width & $1 \mathrm{~ms}$ & $100 \mathrm{~ns}$ & $100 \mathrm{fs}$ \\
Intensity $\left(\mathrm{W} / \mathrm{cm}^{2}\right)$ & $10^{6}$ & $10^{8}$ & $10^{15}$ \\
Average power $(\mathrm{W})$ & $100-1000$ & $100-1000$ & $1-10$ \\
Machining quality & Poor & Good & Excellent \\
Throughput/speed & High & High & Very low \\
Cost of ownership & Low & Medium & High
\end{tabular}

\subsection{The material.}

The question what is short and what is ultrashort can be discussed also from the viewpoint of the material. The material is subjected to a beam of photons coming from outside which is absorbed in a skin layer.

The photons are absorbed in that skin layer by the free electrons, in about $1 \mathrm{fs}$. $\left(10^{-15} \mathrm{~s}\right)$. The relaxation time of the electrons is about one ps $\left(10^{-12} \mathrm{~s}\right)$. During that time the energy is stored in the electrons, after the relaxation time it is converted into heat.

The intensity of the incoming beam is expressed by $I_{0}$. The decrease of the laser intensity in the depth is given by $1=I_{0} e^{-\alpha x}$ where $\alpha$ the optical absorptivity of the material and $x$ the depth into the material. An important quantity is the penetration depth $\delta(\delta=2 / \alpha)$ in which almost all laser energy is absorbed. This optical penetration depth is for metals in the order of $10 \mathrm{~nm}$. It means that the laser energy heats a $10 \mathrm{~nm}$ thick layer of metal in one ps.

This heat will diffuse from that skin layer to the bulk. The diffusion depth is expressed by $d=\sqrt{ } 4$ at with $a$ as the thermal diffusivity and $t$ the diffusion time.
In case of steel we obtain in $10 \mathrm{fs}$ a diffusion depth of 1 $\mathrm{nm}$ while during a $1 \mathrm{ps}$ pulse the heat diffuses over 10 $\mathrm{nm}$. Taking the results together than we see that:

- $\quad$ it takes 1 ps to convert laser energy into heat this takes place in a $10 \mathrm{~nm}$ thick skin layer the diffusion depth for $1 \mathrm{ps}$ is also $10 \mathrm{~nm}$

From these results we consider a pulse as ultrashort when the (thermal) diffusion depth during the pulse is in the same order or less than the skin layer depth (optical penetration depth)

The optical penetration depth depends on the material and the laser wavelength. The diffusion depth depends on the material properties. Table 2.2 gives some numbers for different materials. Since especially for glass and plastics the material can be more or less transparent for certain wavelengths this is just a rough indication. Detailed information is given by Bosman [5]. In general we will consider pulses shorter than one picosecond as ultrashort.

Table 2.2. Ultrashort pulses times for some materials.

\begin{tabular}{ll}
\hline Material & Pulse length \\
\hline Metals & $1 \mathrm{ps}$ \\
Ceramics & $10 \mathrm{ps}$ \\
Plastics & $1 \mathrm{~ns}$
\end{tabular}

Based on physical considerations a removal rate of 10 $\mathrm{nm} /$ pulse at $\mathrm{F}=1 \mathrm{~J} / \mathrm{cm}^{2}$ is expected on steel, while an excess of laser fluence is spilled. Experiments at Lawrence Livermore Nat Lab (Figure 2.2), however, show higher yields of $50 \mathrm{~nm} /$ pulse at $F=4 \mathrm{~J} / \mathrm{cm}^{2}$ up to 350 $\mathrm{nm} /$ pulse at $\mathrm{F}=14 \mathrm{~J} / \mathrm{cm}^{2}$ which is the saturation limit according to Semak [6]. These results are explained by the interaction with the hot solid plasma that is formed during the pulse and which is expected to evaporate metal even after the pulse has been finished.

According to Semak, there is no detailed knowledge about the real interaction processes during femtosecond laser pulses up to now. Computer simulations however, based on three-dimensional molecular dynamics, will give some insight in the interaction phenomena. Ohmura [7- 
10], (Figure 2.3) has simulated the interaction and ablation behaviour of aluminium, copper and silicon at $266 \mathrm{~nm}$ wavelength. The optical penetration depth was 7 , 12 and $5 \mathrm{~nm}$ respectively. The applied power density was in the range of 5 to $50.10^{9} \mathrm{~W} / \mathrm{cm}^{2}$. It was found that the material evaporates as small particles $(0.3-10 \mathrm{~nm})$, most of them smaller than $1 \mathrm{~nm}$. The average velocity of

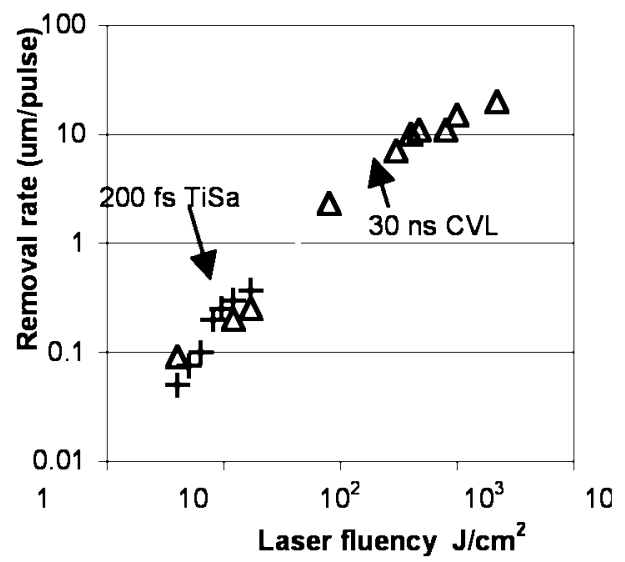

Figure 2.2. Material removal rates for two lasers. $\Delta$ : Copper vapor laser $30 \mathrm{~ns},+$ : Ti: sapphire laser 200 fs

the particles is several $\mathrm{km} / \mathrm{s}$ or more, but there are also particles whose velocities are negative. They are returning to the substrate causing some deposition of debris. Another effect found by simulation was the generation of dislocation slip planes and vacancies due to shock waves acting until $50 \mathrm{~nm}$ below the surface.

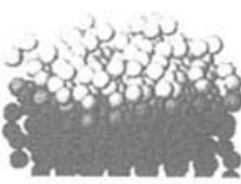

time $0.2 \mathrm{ps}$

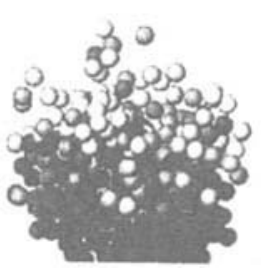

1 ps

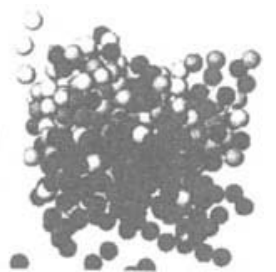

3 ps
Figure 2.3. Ablation of silicon by a $200 \mathrm{fs}, 510^{10} \mathrm{~W} / \mathrm{cm}^{2}$ laser pulse. The $5 \mathrm{~nm}$ thick layer is released from the surface within 3 ps [8]

\subsection{Generation of short laser pulses}

The mechanism for generating laser pulses lies in the nature of the active laser medium and the corresponding lifetimes of the atomic energy levels. With pulsed lasers much higher peak powers can be reached making these sources attractive for numerous applications in industrial production. By using different pulse generation techniques (Figure 2.4), the pulse duration, pulse energy and reproducibility can be modified over wide ranges.

\section{-Gain switching}

Gain switching can be regarded as the most direct method to generate laser pulses. During gain switching the pumping process is modulated which results in switching the amplification in the laser medium. After the pumping process has been switched on, the population inversion starts to build up. The laser starts to oscillate when the critical inversion is reached, i.e. the gain becomes larger than losses. The oscillation continues until the pumping process is switched off, or until the losses become higher than the amplification. The reproducibility and stability tends to be stochastic, which makes gain switching, in spite of its simplicity, inapplicable for many applications. Pulse duration available from flash lamp pumped solid-state lasers by gain switching can vary between $10 \mu \mathrm{s}$ up to $10 \mathrm{~ms}$.

\section{- Q-switching}

The output of a gain switched, pulsed solid-state laser is generally a train of irregular pulses - irregular in peak power, pulse width and repetition frequency. It is possible to remove these irregularities and at the same time greatly increase the peak power by a technique called Qswitching. Q-switched lasers normally emit only one giant pulse in an operational cycle. The pulse length is typically less than a microsecond down to several nanoseconds and peak powers between $10^{6} \mathrm{~W}$ and $10^{9} \mathrm{~W}$. This technique can also be applied to continuously pumped lasers in order to produce a train of Q-switched pulses with regular duration, peak power, and repetition rate. Qswitching is a mode of laser operation in which energy is stored in the laser material during pumping in the form of excited atoms and suddenly released in a single, short burst. This is accomplished by changing the optical quality of the laser cavity. The quality factor $Q$ is defined as the ratio of the energy stored in the cavity to the energy loss per cycle. During pumping the high reflectivity (HR) mirror is effectively removed from the system, resulting in a low $Q$ factor and preventing the onset of laser emission. After a large amount of energy has been stored in the active medium, the HR mirror is returned to proper alignment and operation, and most of the stored energy emerges in a single, short pulse [11]. A $Q$-switch is essentially a shutter placed between the active medium and the HR mirror. With this shutter closed, the HR mirror is blocked preventing oscillation. When the amplifier gain reaches a predetermined value, the shutter is opened to increase the cavity quality

Several techniques can be used for Q-switching of lasers. Mechanical Q-switches can be realized by a light chopper, a spinning disc with a hole, or by a spinning mirror. The chopper is inserted into the optical cavity between the laser rod and the high reflecting mirror. $A$ mechanical chopper is relatively slow. It can switch only a fraction of the beam area at a time as it is swept across the aperture. For this reason, mechanical Q-switches are not practical or effective.

Spinning reflectors are used quite frequently in $Q$ switched systems where it is not necessary to closely synchronize the output to some other event. Usually the high reflecting mirror is rotated so that the mirror is tilted out of alignment. The system is Q-switched when the mirror rotates back into alignment (it is in alignment once each revolution). Switching time is typically a few nanoseconds.

For electro-optic Q-switching a polarization filter and rotator are placed into the reflecting cavity between the laser rod and the reflecting mirror. Rotating the polarization vector of the laser beam inside the cavity results in low cavity feedback so that it cannot pass through the polarization filter. When this polarization rotation is terminated, the cavity reflectivity is high and the system will produce a giant pulse. Two of the electrooptic devices used in this application are Kerr cells and Pockels cells. The Pockels effect is a linear electrooptical effect, i.e. the refraction index change in the parallel and orthogonal direction is proportional to the applied voltage. The Kerr effect is a non-linear electrooptical effect, i.e. the dependency is a square function of the applied voltage. Switching time is fast, typically less than a nanosecond. 
Within acousto-optic Q-switches a transparent element is placed in the cavity. This transparent device, when excited with intense, standing, acoustic waves by piezoelectric crystals, exhibits a diffraction effect on the intracavity laser beam and diffracts part of the beam out of the cavity alignment. This results in a low feedback. When the acoustic wave is removed, the diffraction effect disappears, the cavity is again aligned, and the system emits a giant pulse. Switching time is slow at $100 \mathrm{~ns}$ or greater. Saturable absorbers are available as thin films on glass substrates or as liquids in glass cells. For Qswitching, a dye cell is placed in the laser cavity. The dye absorbs the laser wavelength at high rates at low light intensities, presenting a very high cavity loss to the laser, and preventing lasing until the amplifier has been pumped to a high gain state. When the irradiance from the active medium becomes intense enough, the energy that is absorbed by the dye optically pumps the dye material, causing it to be transparent at the laser wavelength. The dye cell is bleached and causes no longer high cavity losses, i.e. the quality of the resonator increases. The absorption change of the dye is the equivalent of $\mathrm{Q}$-switching in the laser, and it can occur in less than a nanosecond. Their switching time is fast.
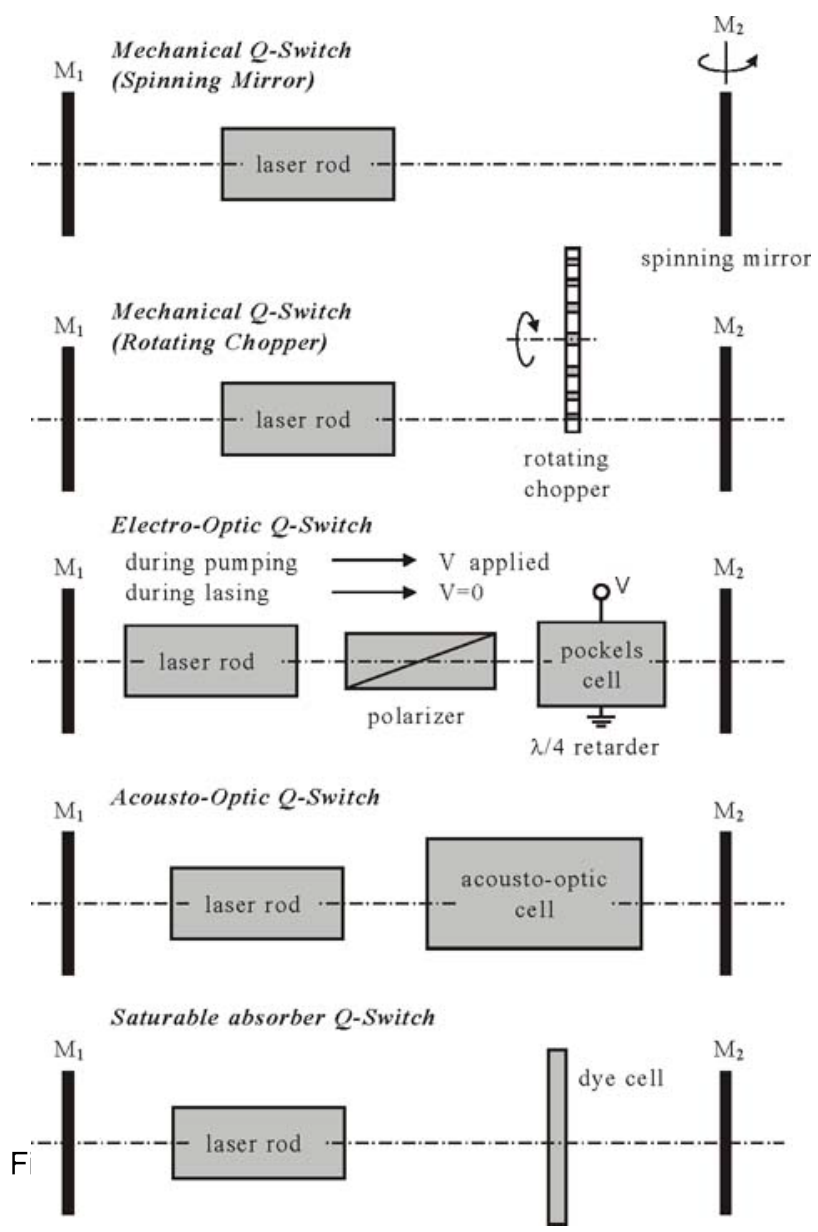

- Mode-locking

While Q-switching can be used to generate pulses with high intensities in the ns-range, mode locking is used to generate ultrashort laser pulses with pulse duration in the ps- to fs-range. Pulses in the ps-range were generated for the first time by passive mode locking of a ruby laser shortly after its discovery by Mocker in the mid 60s [12]. Mode locking can be used very effectively for lasers with a relatively broad laser transition bandwidth, and thus for lasers with a broad amplification profile, in which numerous longitudinal modes can oscillate simultaneous- ly. Assuming that $2 \mathrm{~N}+1$ modes oscillate with the same amplitude $E_{0}$ and a constant phase relation between the modes, the resultant field amplitude $E_{\text {tot }}$ can be expressed as a function of the time t. The superposition of the single modes with a constant phase difference leads to laser pulses with a duration $t_{p}$. The peak intensity $I_{p}$ of the single pulses (Figure 2.5 ) is given by:

$I_{p}=(2 N+1)^{2} I_{0}$

Thus, the peak intensity is $(2 \mathrm{~N}+1)$ times the sum of the single intensities when the oscillating modes are random coupled.

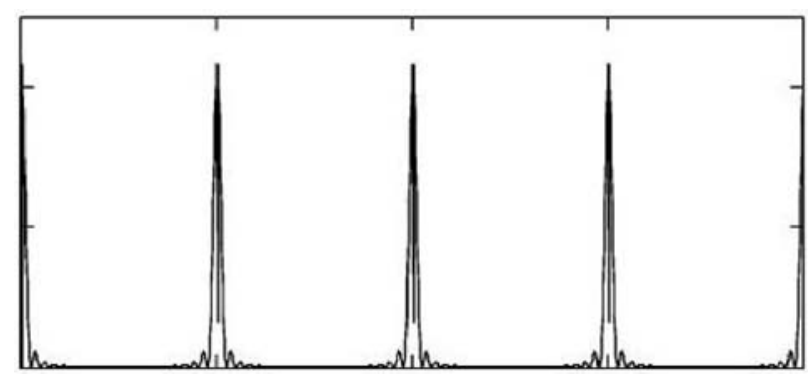

Figure 2.5. High peak intensities by Mode-locking

The broader the spectral bandwidth of the transition and the higher the number of modes for which the threshold amplification is exceeded, the shorter laser pulses can be generated. For achieving the mode-locking condition, active and passive mode-locking techniques can be used.

Active mode-locking implies that the resonator is equipped with a modulator, which is triggered by an external signal in such a way that a sinusoidal modulation of the losses in the optical resonator takes place. The frequency is equal to the frequency distance of the longitudinal modes. Initially, this loss modulation represents an amplitude modulation with the frequency of the mode, which starts to oscillate first at a maximum amplification at the frequency. This modulation then induces the neighbouring modes with the frequencies, which experience an amplitude modulation as well. This process continues until all longitudinal modes within the amplification bandwidth of the laser are coupled and synchronized. The induction of the side bands automatically results in the constant phase relation. Generally, electro-optic and acousto-optic modulators can be used. Flash lamp-pumped solid-state lasers typically produce pulse durations of 100 ps, with Nd:YAG and 30 ps with Nd:YLF using active mode locking. Diodepumped Nd:YLF lasers with active mode locking are even able to provide laser pulses below 10ps.

Passive mode locking is based on the same principle as active mode locking, which is a temporal modulation of the resonator losses. In contrast to active mode locking, the laser system itself determines the point in time at which the losses are at their minimum [13]. The loss modulation takes place either by means of an intensity dependent absorption, which is caused by a saturable absorber [14] or the use of the Kerr effect [15]. Due to the fact that many modes oscillate simultaneously in an oscillator with a broad amplification bandwidth, the intensity initially shows a statistic temporal behaviour. Such time dependent intensity automatically causes a temporal loss modulation in the absorber. This gradually leads to an order with a constant phase relation between the individual longitudinal modes, which behaviour can be theoretically described by the fluctuation model.

In passive mode locking using saturable absorbers, mode locking starts from normal noise fluctuations in the laser cavity. Once a noise spike exceeds the threshold of saturating an absorber, the losses decrease, and gain 
increases in the round trip. Thus initiated spike begins to grow, and becomes shorter, until a stable pulse duration is obtained. As a rule, an absorber cuvette with a length of $100 \mu \mathrm{m}$ is being placed in the resonator. The advantage of this set-up is that the reflected front flank of the pulse and the approaching back flank of the pulse interfere inside the absorber, which results in a saturation at lower intensities. Currently, for the generation of ultrashort laser pulses in solid-state lasers usually Kerrlens mode locking is applied. This method uses the nonlinear Kerr-effect, i.e. the dependency of the refractive index from the incident intensity. If a laser beam with high intensity and Gaussian profile passes a Kerr medium the refractive index is not spatially constant due to the intensity profile. According to the high intensities close to the center of the laser beam, the refractive index and, accordingly the optical path, are high compared to the outer regions. Consequently, the Kerr-medium acts as a gradient index lens and is, therefore, called Kerr-lens. For Kerr-lens mode locking, an aperture is installed in the focal point of the Kerr-lens which is big enough to let the focused pulsed beam pass and to block most of the low intensity radiation. This intracavity aperture lets the mode-locked pulses with high intensities pass and blocks the modes with random phase relation and low intensity level until they get the right phase relation by accident. The aperture can either be realized by a slit or by arranging a tailored pumping region in the active material. The combination of the Kerr-medium with the aperture then acts as a saturable absorber.

\section{OVERVIEW OF LASERS AND APPLICATION FIELDS}

Table 3.1 gives an overview of the (short) pulsed lasers for various applications

Table 3.1. Short pulsed lasers

\begin{tabular}{cccc}
\hline Laser & $\begin{array}{c}\text { Wave- } \\
\text { length } \\
(\mathrm{nm})\end{array}$ & $\begin{array}{c}\text { Pulse } \\
\text { length }\end{array}$ & $\begin{array}{c}\text { Frequency } \\
\mathrm{KHz}\end{array}$ \\
\hline $\mathrm{TEA} \mathrm{CO}_{2}$ & 10600 & $200 \mu \mathrm{s}$ & 5 \\
$\mathrm{Nd}: \mathrm{YAG}$ & $\begin{array}{c}1060,532, \\
355,266\end{array}$ & $\begin{array}{c}100 \mathrm{~ns} \\
10 \mathrm{~ns}\end{array}$ & 50 \\
Excimer & $193-351$ & $20 \mathrm{~ns}$ & 0.5 \\
Copper & $611-578$ & $30 \mathrm{~ns}$ & $4-20$ \\
vapor & & $100 \mathrm{fs}$ & 1 \\
TiSaphire & 775 & & \\
\hline
\end{tabular}

The passively Q-switched micro lasers $[16,17]$ open new ways for micro machining. A continuous wave diode laser of about $1 \mathrm{~W}$ is used to pump a laser material with a saturable absorber on the output window. When this solid state Q-switch reaches the threshold it becomes transparent within a nanosecond and a short pulse $(0.3$ to $1.5 \mathrm{~ns}$ ) is delivered. Repetition rates are between 2 and $50 \mathrm{kHz}$. An overview of laser micromachining applications is in Table 3.2
Table 3.2. Laser micromachining applications [18]

\begin{tabular}{|c|c|c|}
\hline Laser & Applications & Material \\
\hline \multicolumn{3}{|c|}{ Microelectronics packaging } \\
\hline Excimer & $\begin{array}{l}\text { Via drilling and } \\
\text { interconnect } \\
\text { drilling }\end{array}$ & $\begin{array}{l}\text { Plastics, } \\
\text { ceramics, silicon }\end{array}$ \\
\hline $\begin{array}{l}\text { Lamp-based } \\
\text { solid-state }\end{array}$ & $\begin{array}{l}\text { Via drilling and } \\
\text { interconnect } \\
\text { drilling }\end{array}$ & $\begin{array}{l}\text { Plastics, metal, } \\
\text { ceramics, silicon }\end{array}$ \\
\hline $\begin{array}{l}\text { Diode-pumped } \\
\text { solid-state }\end{array}$ & $\begin{array}{l}\text { High volume via } \\
\text { drilling, tuning } \\
\text { quart } \\
\text { oscillators }\end{array}$ & $\begin{array}{l}\text { Plastics, metal, } \\
\text { inorganic }\end{array}$ \\
\hline $\begin{array}{l}\mathrm{CO}_{2} \text { sealed or } \\
\text { TEA }\end{array}$ & $\begin{array}{l}\text { Excising and } \\
\text { scribing of circuit } \\
\text { devices, large } \\
\text { panel via drilling, }\end{array}$ & $\begin{array}{l}\text { Ceramics, } \\
\text { plastics }\end{array}$ \\
\hline \multicolumn{3}{|c|}{ Semiconductor manufacturing } \\
\hline Excimer & $\begin{array}{l}\text { UV lithography } \\
\text { IC repair, thin } \\
\text { films, wafer } \\
\text { cleaning }\end{array}$ & $\begin{array}{l}\text { Resist, plastics, } \\
\text { metals, oxides } \\
\text { silicon }\end{array}$ \\
\hline $\begin{array}{l}\text { Lamp-based } \\
\text { solid-state and } \\
\text { Diode-pumped } \\
\text { solid-state }\end{array}$ & $\begin{array}{l}\text { IC repair, thin } \\
\text { films, bulk } \\
\text { machining } \\
\text { resistor and } \\
\text { capacitor } \\
\text { trimming }\end{array}$ & $\begin{array}{l}\text { Plastics, silicon, } \\
\text { metals, oxides } \\
\text { silicon, thick film }\end{array}$ \\
\hline $\mathrm{CO}_{2}$ or TEA & $\begin{array}{l}\text { Excising, } \\
\text { trimming }\end{array}$ & Silicon \\
\hline \multicolumn{3}{|c|}{ Data-storage devices } \\
\hline Excimer & $\begin{array}{l}\text { Wire stripping } \\
\text { air bearings, } \\
\text { heads micro via } \\
\text { drilling }\end{array}$ & $\begin{array}{l}\text { Plastics, glass } \\
\text { silicon ceramics } \\
\text { plastics }\end{array}$ \\
\hline $\begin{array}{l}\text { Diode-pumped } \\
\text { solid-state }\end{array}$ & $\begin{array}{l}\text { Disk texturing } \\
\text { servo etching } \\
\text { micro via drilling }\end{array}$ & $\begin{array}{l}\text { Metal, ceramics } \\
\text { metals, plastic }\end{array}$ \\
\hline $\mathrm{CO}_{2}$ or TEA & Wire stripping & Plastics \\
\hline \multicolumn{3}{|l|}{ Medical devices } \\
\hline Excimer & $\begin{array}{l}\text { Drilling catheters } \\
\text { balloons, } \\
\text { angioplasty } \\
\text { devices. Micro } \\
\text { injection orifice } \\
\text { drilling blood cell } \\
\text { slices }\end{array}$ & $\begin{array}{l}\text { Plastics, metals } \\
\text { ceramics, } \\
\text { inorganics }\end{array}$ \\
\hline $\begin{array}{l}\text { Lamp and } \\
\text { Diode-pumped } \\
\text { solid-state }\end{array}$ & $\begin{array}{l}\text { Stents, } \\
\text { diagnostic tools }\end{array}$ & Metals \\
\hline $\mathrm{CO}_{2}$ or TEA & Orifice drilling & Plastics \\
\hline \multicolumn{3}{|c|}{ Communication and computer peripherals } \\
\hline Excimer & $\begin{array}{l}\text { Cellular phone, } \\
\text { fiber gratings, } \\
\text { flat panel } \\
\text { annealing, ink } \\
\text { jet heads }\end{array}$ & $\begin{array}{l}\text { Plastics, silicon, } \\
\text { glass, metals, } \\
\text { inorganics }\end{array}$ \\
\hline $\begin{array}{l}\text { Lamp and } \\
\text { Diode-pumped } \\
\text { solid-state }\end{array}$ & $\begin{array}{l}\text { Via interconnect } \\
\text { coating removal } \\
\text { tape devices }\end{array}$ & $\begin{array}{l}\text { Plastics, metals, } \\
\text { oxides, ceramics }\end{array}$ \\
\hline $\mathrm{CO}_{2}$ or TEA & Optical circuits & Glass, silicon \\
\hline
\end{tabular}




\section{SOLID STATE PULSED LASERS}

\subsection{Introduction}

A variety of tools are used for micro machining, including high precision turning (Weck [19]), electric discharge (Kruth [20]) or electron- and laser beams. Each has a different mechanism for energy coupling, such as mechanical heating of the cut edge as well as Joule heating of the current density (volume source and homogeneous Neumann type ${ }^{1)}$ boundary condition) and scattering and absorption of electrons and photons within a few tenths of an Angstrom (Neumann type boundary conditions) up to a few centimeters depending on material and photon energy [21]

Two types of pulsed lasers, excimer lasers and solid state lasers, are widely used in industrial production for generating a structure size in the range of $130 \mathrm{~nm}$ (for example Pentium 4 lithography) and for laser ablation by melting and vaporization of material with structure sizes of $0.1 \mathrm{~mm}$ and form accuracy of $1-10 \mu \mathrm{m}$. Excimer lasers are based on gas discharge and operate in the UV wavelength. Solid-state lasers are applied with lamp pumped crystals designed as first generation diode pumped lasers where diode lasers substitute the lamp while the resonator design remains almost unchanged.

The domains of excimer lasers are applications that need high average output powers (up to several $100 \mathrm{~W}$ ) and large pulse energies in the UV wavelength regime. Excimer lasers offer large pulse energies $(10 \mathrm{~mJ}$ to $1 \mathrm{~J}$ ) at pulse durations around 30 ns by a discrete UV wavelength between 157 and $355 \mathrm{~nm}$. Typical applications are: UV lithography, annealing of LCD displays, eye surgery and surface treatment by mask imaging techniques.

Solid state lasers with a wave length of $1.06 \mu \mathrm{m}$ based on Nd:YAG and Nd:Vanadat crystals are widely used for marking and micro structuring processes in industry. With the option of non-linear frequency conversion to $532 \mathrm{~nm}$, $355 \mathrm{~nm}$ and $266 \mathrm{~nm}$ laser characteristics and material properties like wavelength dependent absorption can be matched.

Diode pumped solid state lasers are, compared to excimer lasers, more compact, nearly maintenance free, and offer better beam quality which enables direct processing and a wider range of wavelength, pulse durations and pulse frequency. Different types of solidstate lasers are used. They can be labelled by pulse energy $E_{p}$ average power $P$ and pulse duration $t_{p}$

Conventional lamp pumped, acousto-optic Q-switched lasers $\left(E_{p}>10 \mathrm{~mJ}, P=10-200 \mathrm{~W}, t_{p}=60\right.$ ns to several $100 \mathrm{~ns}$ ) are widely used in low cost systems for marking applications. Electro-optic Q-switched lasers offer shorter pulse durations and higher pulse powers $\left(E_{p}<1 \mathrm{~mJ}, P=\right.$ $1-30 \mathrm{~W}, t_{\mathrm{p}}>5-20 \mathrm{~ns}$ ), they are used for structuring and drilling. Higher output powers (up to the $\mathrm{kW}$ level) are gained by amplification of the oscillator pulses in a separate amplifier module.

Advances in tailoring of the optical energy density will enable prospective applications

1) There are three kinds of boundary conditions:

a. Dirichelet boundary conditions: the temperature is prescribed at the boundary

$b$. Neumann type boundary condition means that the temperature at the boundary directly follows from the prescribed heat flow (example: radiation).

c. Robin boundary conditions: a combination of temperature and heat flux is prescribed at the boundary and both, temperature and heat flux are parts of the solution (example: Phase transformations).
The most valuable parameters of the achievable laser performance are shown in Figure 4.1: pulse energy $E_{0}$ $[\mathrm{mJ}]$, repetition rate $v_{\text {rep, }}$ pulse duration $t_{p}$, and beam quality $M^{2}$. For the highest beam quality $\left(M^{2}=1\right)$ beam is diffraction limited. The key properties are beam quality and output power -improved simultaneously at high efficiency- as well as compact design. The combination of enhanced capabilities for tailoring the optical energy density with new laser systems and improved processing strategies using the advanced ps-lasers as well as lasers with only a few ns pulse duration [22] leads to further improvement.

Actual developments enable new applications like marking in the middle of transparent materials as well as polishing of metal parts (Figure 4.5), micro machining of transparent material (Figures 4.7 and 4.8) with higher form accuracy and also generation of EUV radiation at 13 $\mathrm{nm}$ wavelength for next generation lithography. Beyond metals and ceramics also materials like diamond and semiconductors as well as very weak materials like silicon and rubber can be processed. Theoretical aspects of actual approaches leading to new laser sources and their applications are presented in the next paragraph.

\begin{tabular}{l}
$\begin{array}{l}\text { Industrial Laser Systems } \\
\text { Industrial Applications } \\
5-50 \mathrm{kHz},>100 \mathrm{~ns}, \mathrm{M}^{2}=10-50\end{array}$ \\
$\begin{array}{l}\text { drilling, structuring, cleaning } \\
10^{-12}\end{array}$ \\
slab end pumped, $4 \mathrm{~mJ}, 5 \mathrm{kHz}, 5 \mathrm{~ns}, \mathrm{M}^{2}=1.5$ \\
\hline MOPA, $76 \mathrm{~mJ}, 2 \mathrm{kHz}, 14 \mathrm{~ns}, \mathrm{M}^{2}=1.5$ \\
Prospective Applications \\
Generation of EUV-Radiation, \\
13 nm Lithography \\
\hline marking on the inside, polishing
\end{tabular}

Figure 4.1. Roadmap for solid-state laser systems, introduced to industrial applications like drilling, structuring, and cleaning.

\subsection{Fundamentals of laser performance.}

Tailoring the laser performance means to balance the fundamental phenomena involved in the laser action and especially to take full advantage of the diode laser as excitation source for the laser crystal. The mechanisms of excitation, amplification and saturation in the crystal depending on spectral and spatial matching of diode pump volume to the volume of the desired laser mode influence efficiency and beam quality. In conventional side pumped laser designs for example thermo-optical effects introduce thermal lensing and birefringence which reduce beam quality and stable laser operation. As consequence of thermal induced birefringence the state of polarization is changed and optical losses are introduced. Successful resonator design depends on detailed knowledge about the most important physical phenomena today limiting the laser performance. Currently applied designs are:

\section{- Rod end pumped}

The output power is limited by thermo mechanical damage of the crystal even for high strength YAGmaterial and the beam quality and scalability of output power is limited by thermal lensing

\section{- Rod side pumped}

The beam quality is limited by birefringence, since the thermal lens becomes polarization dependent. In spite of these limitations actual development of industrial 
solutions for robust and economical power amplifier for Next Generation EUV-Lithography are based on rod side pumped modules.

- Slab side pumped (conventional, almost the whole slab volume is excited)

The amplifier gain is limited by parasitic modes. The laser emission is not gain guided and therefore additional, parasitic modes are amplified outside the fundamental mode volume. The output power is limited by thermo mechanical damage of the crystal. In particular excitation and heating at the corners and edges of the crystal are critical.

\section{- Innoslab end pumped (Figure 4.3)}

The scalability of the laser power at high beam quality is limited by the spatial homogeneity of the pump radiation in the scaling direction (Figure 4.3, x-direction). Shaping of the diode laser beam by optical integrators is the challenge.

\section{- Disc end pumped}

The thin $(100 \mu \mathrm{m})$ disc concept [23] relies on multi pass excitation and high regenerative amplification in order to compensate the small crystal volume. Optical arrangement of multi pass excitation instead of thermal management becomes crucial for the beam quality. In comparison to the end pumped slab Innoslab both heat exchange and reflection of the laser light takes place at the mounted surface of the disc. One challenge is to handle both demands - thermo-mechanical robustness for reliable heat exchange and high optical quality simultaneously

Actually the disc and the Innoslab are the most promising concepts for the resonator design and their potentials are not fully discovered. Suitable matching of diode laser characteristics and resonator design is the challenge of actual development to enable the advanced laser performance of diode pumped solid-state lasers of the second generation

\subsection{Advances in laser performance}

New laser sources like diode pumped solid-state lasers and diode lasers lead to improved beam quality, efficiency and compactness compared to conventional $\mathrm{CO}_{2}$ and lamp pumped lasers. In the past four years the first generation of diode laser based new laser sources have been introduced into industrial production. Actually first prototypes of the second generation of diode pumped solid-state lasers are ready for use. Beside improvements in efficiency and beam quality these laser sources provide short ( $n s$ ) and ultrashort ( $p s$ and fs) pulses with very high pulse powers, leading to improved process efficiencies and new fields of laser application.

Advances in the design of crystal cooling and excitation by diode lasers enable the second-generation solid-state lasers to become very efficient and compact tools for a wider range of pulse parameters. Additionally new types of lasers crystals like Yb:YAG [24] or Yb:KGW can be used. The simple two-level electronic structure of the $Y b$ ion avoids undesired loss processes such as upconversion, excited state absorption, and concentration quenching. Compared with the commonly used Nd:YAG crystal Yb:KGW crystal has a much larger absorption bandwidth, 3 or 4 times longer emission lifetime in similar hosts with enhanced storage capacity

Disc lasers and end pumped slab lasers allow average powers up to the $\mathrm{kW}$ regime and beam qualities comparable to a $\mathrm{CO}_{2}$-laser. While disk lasers have been proven to provide good $\mathrm{CW}$ performance, pulse performance is limited by comparable low pulse energy and low gain, leading to 100 ns pulses in Q-switched operation. Mode locked oscillators generating ps pulses at more than $100 \mathrm{~W}$ average output power have been demonstrated.

Slab lasers provide highest beam quality at $\mathrm{kW}$ output level and the ability of short pulse generation (5 to $10 \mathrm{~ns}$ ) in $Q$-switch mode. High gain lead to efficient single pass amplification for example amplification of a $4 \mathrm{~W}$ signal at $7 \mathrm{ps}$ pulse duration and $100 \mathrm{MHz}$ repetition rate to about $50 \mathrm{~W}$ average power with a single amplifier stage as shown in Figure 4.2.

Most ps-systems are also build up in Master Oscillator Power Amplifier (MOPA) configurations; ps pulses with average output power of several $W$ are generated by mode locked solid state lasers and amplified by regenerative and/or high gain single- or multipass amplifiers. These lasers are mostly on a laboratory level.

Material processing with ultrashort-pulses $\left(E_{p}<100 \mathrm{~mJ}\right.$, $P=1 \mathrm{~mW}$ to $100 \mathrm{~W}, t_{\mathrm{p}}>10-150 \mathrm{fs}$ ) is actually under investigation. There are only a few fs-laser systems used in production, see par. 4.8. Next generation fs-lasers are expected to be direct diode pumped in order to reduce system size and costs. First laser sources based on crystals like Cr:LiSAF and Cr:LiSGAF have been demonstrated. Amplifier prototypes will be available soon.

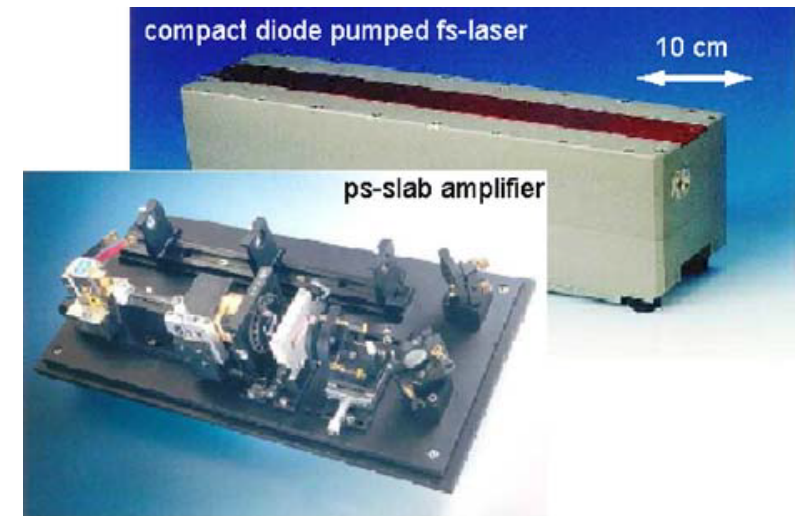

Figure 4.2. Compact diode pumped fs-laser are ready for use with 30 fs pulse duration and $90 \mathrm{MHz}$ repetition rate emitting $135 \mathrm{~W}$ of averaged output power at $880 \pm 25 \mathrm{~nm}$ wavelength $\left(\mathrm{M}^{2}<1.3\right)$. A ps-slab amplifier on laboratory scale emitting $48 \mathrm{~W}$ of averaged output power with 8 ps pulse duration and 80 to $120 \mathrm{MHz}$ repetition rate.

\subsection{Resonator design}

The core issue by scaling the output power at high beam quality is the thermal management to maintain high beam quality. An effective design is given by diode end pumped slab laser [25], a slab-shaped crystal with two polished end faces only for passing the pumping beam and the laser beam. The waste heat in the crystal is effectively removed by its two large faces, which are thermally contacted to heat sinks (Figure 4.3).

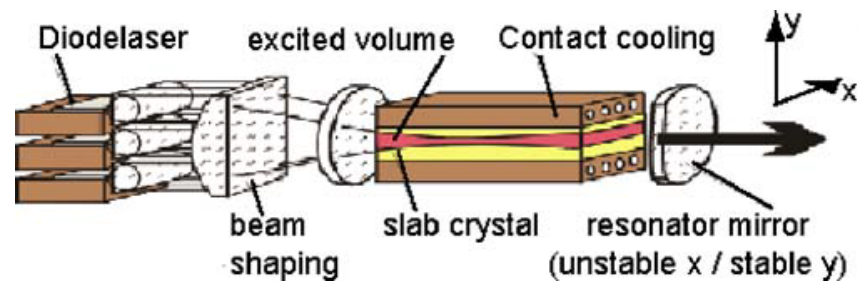

Figure 4.3. The Innoslab concept takes advantage of gain-guided generation of laser radiation. Homogeneous excitation by beam shaping of the diode laser is a key feature. 
A diode laser stack pumps the slab crystal. They have to match the emission and absorption spectra as well as the spatial volume of pump mode and the laser mode. The excitation and amplification is gain guided inside the slab having a line shaped cross section, which underfills the cross section of the slab. A hybrid resonator-stable in the plane of small gain dimension (high beam quality) and off-axis unstable (high power) in the plane of large gain dimension- is used for getting high efficiency at diffraction limited beam quality. The resonator has a length of some $\mathrm{cm}$ since the time for one round trip in the resonator limits the achievable pulse length and repetition rate

The slab design takes (spatial and spectral) advantage of the diode lasers. In particular the line shaped diode laser beam is diffraction limited in the fast direction (Figure 4.3, $y$-direction) where it matches the requirements of gain guiding. Simultaneously, the line shaped diode laser beam with low beam quality in the slow direction (Figure $4.3, x$-direction) matches the slab shape. In combination with the cooling design end pumped slab laser has a compact size, efficient cooling in one spatial direction (low thermal lensing), proper overlap of the excited and laser mode volumes (high efficiency and beam quality). Short pulses in Q-switch operation are achieved and the power is expected to be scalable at diffraction limited beam quality by increasing the extent of the slab the length of the line shaped diode laser beam (Figure 4.3, $x$ direction).

Based on the end pumped slab laser concept the Fraunhofer Institute for Laser Technology and the Company EdgeWave have developed an electro-optically $Q$-switched laser. The laser delivers an output power as high as $50 \mathrm{~W}$ at a repetition rate of $45 \mathrm{kHz}$. Figure 4.4 shows a typical pulse shape. The pulse length is about 5 ns at $5 \mathrm{kHz}$. The pulse energy reaches $5 \mathrm{~mJ}$ at $5 \mathrm{kHz}$. The pulse peak power is as high as $800 \mathrm{~kW}$, which is of interest for efficient frequency conversion. The beam quality is almost diffraction limited. The high peak power and high beam quality can be used for engraving inside transparent materials (Figure 4.5).

In this case the laser beam is focused into the transparent material. The extremely high intensity of about $400 \mathrm{GW} / \mathrm{cm}^{2}$ at the focus leads to localized absorption and optical breakdown in the volume of the material. The absorbed laser energy generates a micro deformation, which scatters the light (Figure 4.5, inlet).

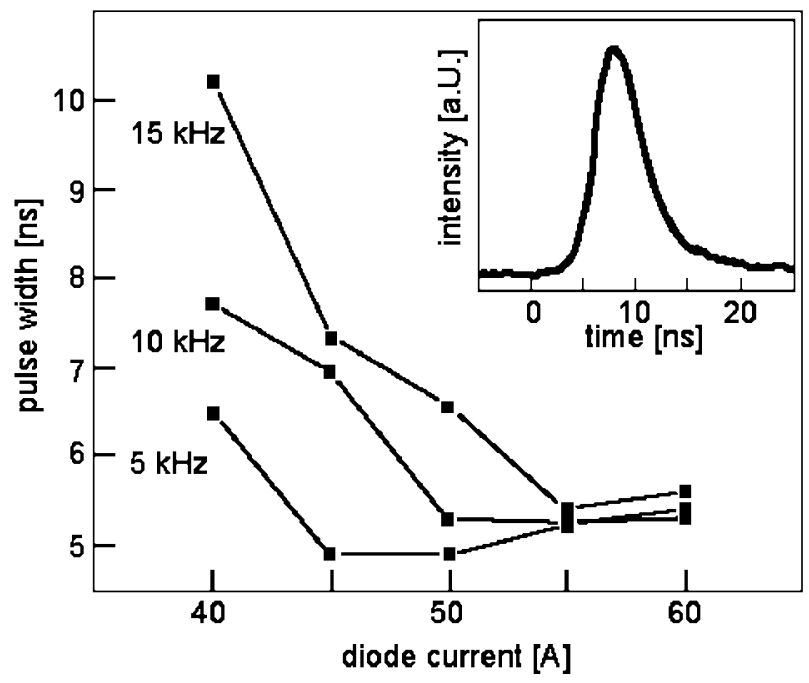

Figure 4.4. With the Innoslab concept shortest pulse durations of about $5 \mathrm{~ns}$ at $5 \mathrm{kHz}$ repetition rate are demonstrated emitting a high quality nearly diffraction limited $5 \mathrm{~mJ}$ laser pulse.

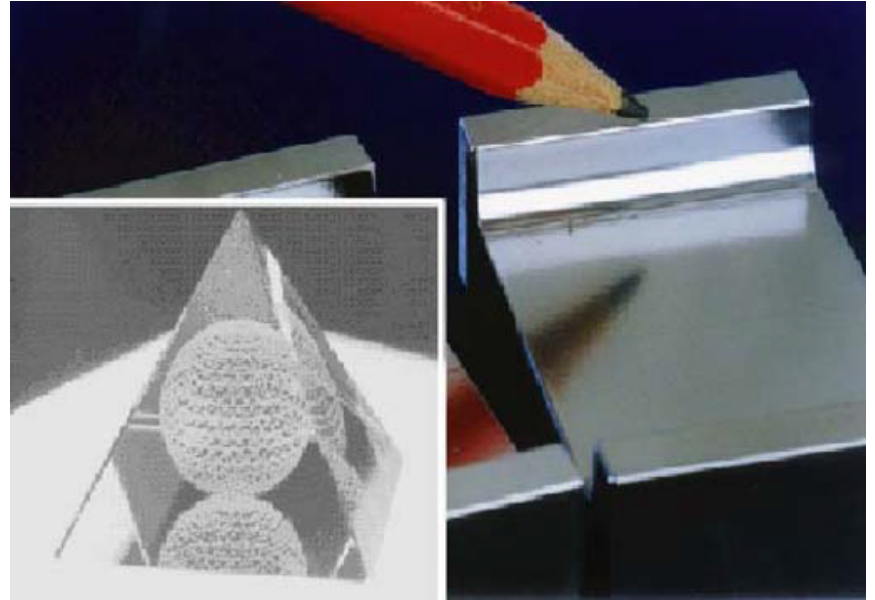

Figure 4.5. Engraving on the inside transparent material generates micro deformations, which are visible by scattering of the light. Laser polishing means remelting with $\mathrm{cw}$-lasers and finishing by short pulse lasers (right).

Moving the focus by a scanner can generate threedimensional pictures. The applications of such process are permanent coding of glass, anti counterfeiting and quality control. The generation of tools for moulding is done mostly manually and is very time consuming. A new application under development is laser polishing, where remelting with $\mathrm{cw}$-lasers does pre-processing and for finishing short pulse lasers are used (Figure 4.5).

\subsection{Power amplifier for EUV-lithography}

The need for microchips with smaller structures requires new technologies of lithography (Next Generation Lithography). With Plasma-sources radiating in the extreme ultraviolet region, structure sizes of 10-13 nm are possible. A promising source for efficient plasma generation from Xenon droplets are diode pumped solid state lasers with short pulses, high repetition rates, average power in the $\mathrm{kW}$-region and excellent beam quality. Reliable economical high power industrial $\mathrm{cw}$ laser modules (ROFIN SINAR) are used for excitation. Such laser modules are available for $\mathrm{cw}$ output powers up to $5 \mathrm{~kW}$. To achieve a beam quality $\mathrm{M}^{2}<10$, which is necessary to provide intensities higher than $10^{12} \mathrm{~W} / \mathrm{cm}^{2}$ on the plasma target, special efforts regarding the compensation of thermal effects (i.e. thermal lensing, thermal induced birefringence) of the laser rods are necessary [26]. The amplifier modules are pumped in $\mathrm{cw}$ mode with high power diode laser bars with a maximum optical pump power of $2000 \mathrm{~W}$ per module. This is because at the repetition rates of $1-10 \mathrm{kHz}$ a pulsed pumping of the $\mathrm{Nd}: Y A G$ rod is not of advantage because of the lifetime of the upper laser level. Numerically optimised optical configurations, consisting of polarization rotators and lenses, between the amplifier modules serve as birefringence compensation and allow a very compact design of the amplifier while maintaining a very high mode overlap to meet the demands for high quality and power. Set-ups with oscillators of repetitions rates up to $10 \mathrm{kHz}$ and 2 amplifiers are demonstrated. Configurations with 4 amplifiers are actually under investigation. The experimental results are used for improvement of the underlying model and the numerical calculations to extrapolate the scalability to 8 amplifier modules. 


\subsection{Processing with higher harmonics}

Generally, laser processing of dielectric materials requires ultraviolet radiation because of the low absorption of the infrared laser wavelength. Non-linear optical effects like frequency conversion require a high beam quality and a high pulse peak power to be efficient. Current laser sources for precision ceramic processing are Q-switched diode pumped solid state lasers (DPSSL) with extra cavity frequency doubling and tripling [27]. The beam profile can be approximated as a Gaussian mode, which results in a near-diffraction, limited beam quality $\left(\mathrm{M}^{2} \leq 1.5\right)$. Beam quality and stability of modern laser sources is prerequisite for most applications. The pulse repetition rate is typically in the range of 1 to $5 \mathrm{kHz}$ and will be increased by actual laser developments. With different beam guiding and shaping devices the focus diameter can be varied between 3 and $20 \mu \mathrm{m}$. A second harmonic conversion efficiency of $65 \%$ is achieved by illuminating a nonlinear crystal (LBO) with the Innoslab (Figure 4.3). The pulse length at the doubled frequency remains below $6 \mathrm{~ns}$ at repetition rate as high as $15 \mathrm{kHz}$

There is a pronounced dependence of absorption on wavelength in the interesting spectral range from 200 to $1200 \mathrm{~nm}$ for ceramic materials (Figure 4.6). The absorptivities have been calculated from the measured reflection and transmission at low intensities with white light lamp. At low intensity illumination the optical properties of the bulk material at low temperatures are detected. The temperature dependence of the optical properties as well as phase transitions and decomposition are not encountered, so that these results cannot give an exact value for the energy deposition during laser processing but they figure out the general course. For example, also materials transparent at low intensities like sapphire can be machined at high intensities or with a rough surface. The absorption increases rapidly in the UV-range for $\mathrm{Al}_{2} \mathrm{O}_{3}$ and $\mathrm{ZrO}_{2}$. For $\mathrm{Si}_{3} \mathrm{~N}_{4}$ and hard metals like tungsten carbide (WC) there is no significant change over the whole spectrum as well as sapphire is nearly transparent.

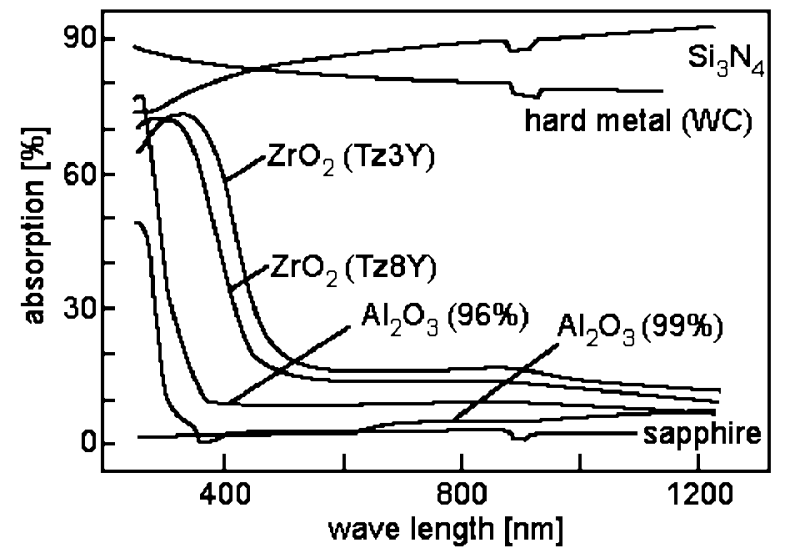

Figure 4.6. The absorption of ceramics depends on wavelength. With the option of efficient nonlinear frequency conversion to $532 \mathrm{~nm}, 355 \mathrm{~nm}$ and $266 \mathrm{~nm}$ laser characteristics and material properties like wavelength dependent absorption can be matched.

Based on the absorption characteristics excimer lasers and frequency tripled Nd:YAG lasers are used yielding low optical absorptions length and high ablation efficiency. Short pulse lasers, especially frequencytripled, diode pumped $\mathrm{Nd}: Y A G$ lasers with a high beam quality offer the possibility to ablate these materials with high quality. With a spot size of about $10 \mu \mathrm{m}$, high fluence ( $>100 \mathrm{~J} / \mathrm{cm}^{2}$ ) can be achieved, so that the materials are vaporized with small amounts of molten material. This technique is applicable for drilling small holes with diameters $\geq 5 \mu \mathrm{m}$ (aspect ratio up to 60) and cutting of thin ceramic substrates (thickness $0.5 \mathrm{~mm}$ ). The edges are sharp and the surface roughness can be reduced to $\mathrm{Ra} \leq 0.1 \mu \mathrm{m}$. Low ablation rates $(0.05 \mu \mathrm{g}$ per pulse) are in favour of controlled micromachining and high precision. The achieved removal depth per pulse has a maximum at a material specific energy density and decreases for higher values. The best quality is achieved at reduced intensity to avoid thermo mechanical damage of the surrounding material. Furthermore the thickness of the recast layer can be reduced down to $<5 \mu \mathrm{m}$ depending on energy per pulse and pulse length. Typical ablation results for $\mathrm{Si}_{3} \mathrm{~N}_{4}$ and diamond are shown in (Figure 4.7)

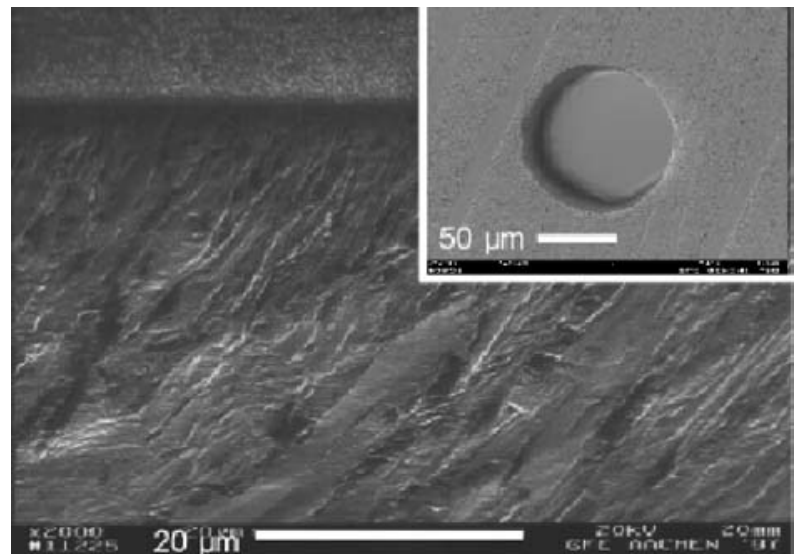

Figure 4.7. Cut edge of $\mathrm{Si}_{3} \mathrm{~N}_{4}$ and polycrystalline diamond $\left(\lambda=355 \mathrm{~nm}, f_{p}=5 \mathrm{kHz}, E_{p}=0.34 \mathrm{~mJ}\right)$

There is a possibility the thermal shock on ceramics can cause damage under the recast layer. Investigations with shorter pulse lengths show no significant damage [28]. At higher energy densities also laser pulses in the fs-range can cause material damage. The machining quality depends on the maximum pressure of the vaporized material. The pulse length dominantly determines the amount of molten material. Three-dimensional microproducts are produced with direct writing were the laser beam moves - in most cases scans - along the workpiece. To get a three-dimensional micro-product the geometry is sliced into several layers comparable to a milling process using CAD/CAM-software. The average depth of a single layer is used as parameter for the calculation of the toolpath. The exact depth of the layer is measured with a white light sensor after removing each layer and compared with the desired value. Deviations are adjusted by varying the process parameters or by recalculating the toolpath

Precise micro-products are produced by $30-50 \%$ overlap. Out of this range the roughness increases steeply [29]. The depth of a single layer and the roughness depend on the energy density. The surface roughness increases at higher aspect ratios of a single pulse crater. A periodic wavy surface is the result, where the period of these waves is not a function of the grid of the laser pulses. As example, the roughness of WC surface processed at a spatial distance between two laser pulses of $10 \mu \mathrm{m}$ contains waves with a period of around $40 \mu \mathrm{m}$. An optimised surface roughness can be achieved with flat removed areas, which means a low aspect ratio. As an example, the pyramid made of WC as part of an embossing tool has a very good surface roughness, comparable to EDM (Figure 4.8). The single ablation steps remove around $1 \mu \mathrm{m}$. Due to the low energy densities no damage by removed grains was detected. The adhesion of the removed material (debris) 
is a very weak, so that the structures can be cleaned easily in an ultrasonic bath

Compared to the combined mask and direct writing technique by Excimer lasers, the direct writing process with a Q-switch Nd:YAG laser offers a higher flexibility concerning the possible shapes, because curved surfaces are generated easily by CAD/CAD. The restrictions are given by the accuracy of the moving system. With this technique three-dimensional structures will be produced in future. The final structures can be used as tools for the production of embossed metal micro parts

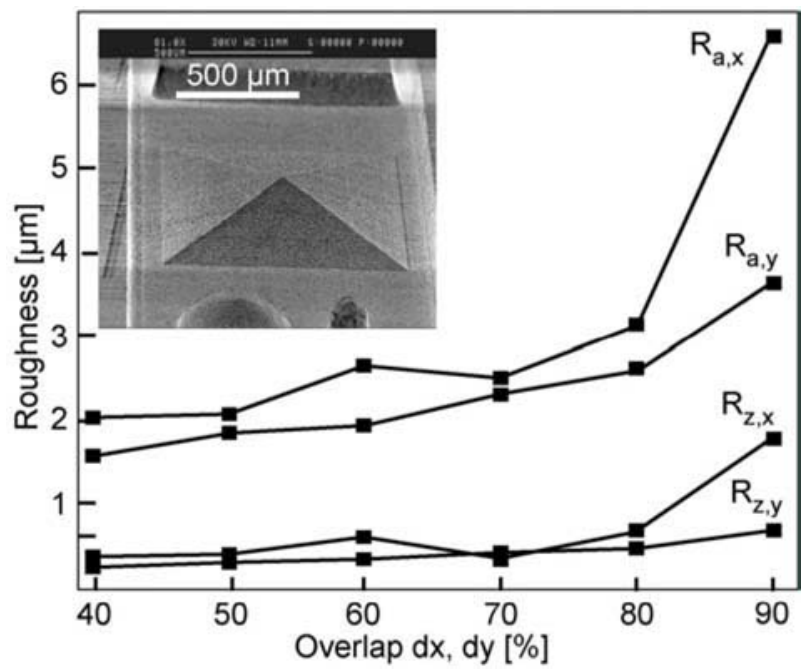

Figure 4.8. Surface roughness of WC after laser micro structuring $\left(\lambda=355 \mathrm{~nm}, \mathrm{f}_{\mathrm{p}}=5 \mathrm{kHz}, E_{p}=0.26 \mathrm{~mJ}\right)$. Inlet: surface of WC-embossing tool $\left(E_{p}=0.3 \mathrm{~mJ}\right)$.

\subsection{Outlook of future laser developments}

Diode pumped solid-state laser systems of the first generation are based on rod laser operation and have improved beam quality in comparison with lamp pumped systems. They represent a simple, compact and robust tool for industrial manufacturing. Also special applications like Next Generation EUV-Lithography rely on power amplifiers with side pumped rods. Further improvement with respect to beam quality is possible but limited by thermal lensing

The slab as well as the disc laser are seen to be the most promising concepts for diode pumped lasers of the second generation, where the resonator design and new dopants as well as host crystals are used to take full advantage of the excitation by diode lasers.

Tailoring the optical energy density with respect to the desired spatial features and dynamical processing domain becomes a broader sense due to the extended range of accessible parameters for the laser performance and its control. Requirements of micro machining and demands on geometrical accuracy will be approached by diode pumped lasers of the second generation.

\subsection{Examples of applications}

\section{Laser cleaning}

Pulsed Nd:YAG lasers are also used in the cleaning and recycling area. G. Spur [30] has developed a process for de-coating compact disks, made of $\Phi 120 \times 1.2 \mathrm{~mm}$ polycarbonate discs coated with $50 \mathrm{~nm}$ aluminium and 10 $\mu \mathrm{m}$ varnish. Due to the recycling economy and waste legislation established in 1996 and the EU waste law for information technology, industry is seeking solutions for an economical and efficient recycling process. It is estimated that of the 10 billion disks annually 3 billion pieces will be collected for recycling. The applied laser is a $50 \mathrm{~W}, 8 \mathrm{~ns} \mathrm{Q}$-switched Nd:YAG laser delivering $2 \mathrm{~J}$ pulses, which chip the aluminium and varnish, and does not influence the transparent polycarbonate. The removal rate at $50 \mathrm{~Hz}$ is $22 \mathrm{~cm}^{2} / \mathrm{s}$ which results in a de-coating time of $5 \mathrm{~s}$ and cost (including handling and labour) of $0.04 \$$ per disk. This is in the same order as the real production costs of a new disk! [31].

Another interesting cleaning application is surface cleaning of silicon wafer by 'laser sparking' which is a gas breakdown caused by an intense laser pulse focussed in the air above the wafer surface. It has been shown by Lee [32] that an airborne plasma shock wave above the surface can successfully remove small particles $(\sim 1 \mu \mathrm{m}$ diameter) such as tungsten, copper and gold from the silicon surface. This contactless cleaning technique is a very efficient, fast and damage-free process. It has superior characteristics compared with conventional laser cleaning employing direct interactions between the laser pulse and the particles. In conventional laser cleaning a fourth harmonic Q-switched Nd:YAG laser (266 nm, 10 ns) is directed on the Si substrate. The small tungsten particles are removed by a rapid thermal expansion of the particle resulting from the laser absorption. This requires fluencies above $0.65 \mathrm{~J} / \mathrm{cm}^{2}$ to overcome the strong adhesion force for smaller particles. The short wavelength is necessary because of the better absorptivity of $\mathrm{W}, \mathrm{Cu}$ and $\mathrm{Au}$ for this wavelength. The fluency, however, must be kept below the threshold fluency of Si damage $\left(0.3 \mathrm{~J} / \mathrm{cm}^{2}\right)$. This is not enough for efficient particle removal in the conventional way. In the new contactless method the striking incoming beam is focussed $2 \mathrm{~mm}$ above the surface at around $10^{11} \mathrm{~W} / \mathrm{cm}^{2}$ causing an optical breakdown of the air resulting in a shock wave of several hundreds MPa $[33,34]$ depending on the distance to the origin. This is well above the adhesion forces of $1 \mathrm{MPa}$ for $1 \mu \mathrm{m}$ and $3 \mathrm{MPa}$ for $0.1 \mu \mathrm{m}$ tungsten particles. Once the bond between the particle and the substrate surface is broken, the detached particles are accelerated to high velocity and blown away by the expansion following the shock wave (Figure 4.9). In this application the fundamental $1064 \mathrm{~nm}$ wavelength of the 10 ns Q-switched Nd:YAG laser can be applied because there is no direct interaction with the particles. The cleaned area per shock is around $2 \mathrm{~cm}^{2}$, which is one order above the conventional technique.

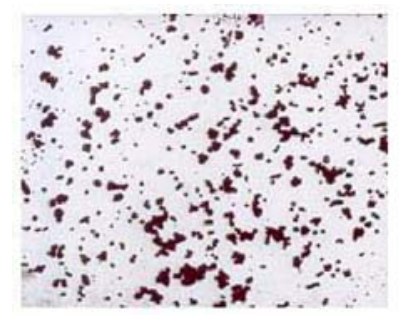

Figure 4.9. Optical micrographs of the silicon surface, (left) before and (right) after the laser shock treatment for the removal of a mixture of submicron $\mathrm{W}, \mathrm{Cu}$ and $\mathrm{Au}$ particles adhered on the surface, Lee [32]

\section{Adjustment:}

Pulsed lasers are applied successfully to adjust micro electro mechanical assemblies. This opens new ways to optimise the design of actuators according to Geiger [35]. Pulsed Nd:YAG as well as excimer lasers are applied to adjust (and bend) various materials as stainless steel, copper alloys or lead frame materials like FeNi42. Hoving [36] describes the adjustment of audio heads mounted on a dedicated adjustment frame (Figure 4.10). Laser pulses on the indicated positions result in a micrometer accuracy fine adjustment. Another application is the adjustment of reed contacts. The intensity of the adjustment pulse is 
based on the measured magnetic field to open/close the contacts (Figure 4.11). A special requirement for this application is that the laserbeam has to pass the green glass enclosure of the reed contacts. Laser adjustment is a flexible alternative for micro bending by sparks. Otsu [37] found the latter more advantageous for highly reflecting materials like copper
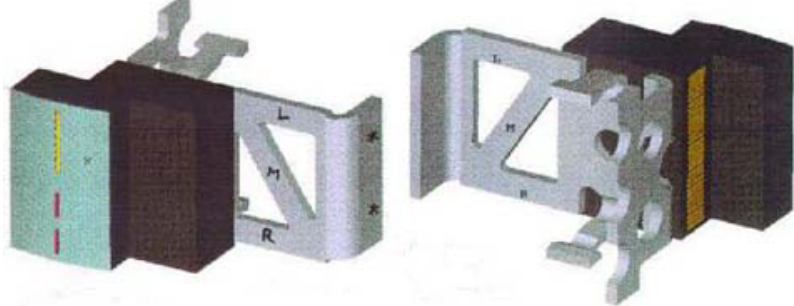

Figure 4.10. Laser fine adjustment of an audio head Laser heating at $L$ rotates the head clockwise (+ azimuth), at $\mathrm{R}$ counter-clockwise (- azimuth). A pulse at $M$, moves the head downwards (+ track height) and at $L$ $+\mathrm{R}$ upwards (- track height) [36].

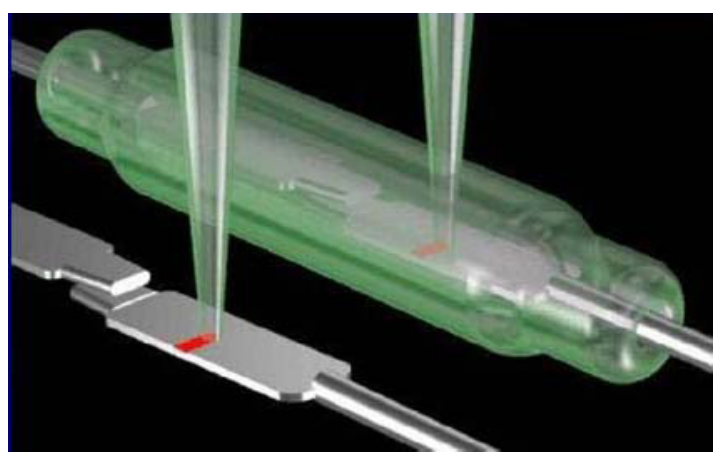

Figure 4.11. Laser adjustment of reed contacts. The distance between the metal reeds determines the value of the magnetic field where the switch closes

\section{EXCIMER LASERS}

\subsection{Introduction and application field}

Excimer lasers are a family of pulsed lasers operating in the ultraviolet region of the spectrum. The laser emission is generated by a fast electrical discharge in a highpressure mixture of rare gas (krypton, argon or xenon) and a halogen gas (fluorine or hydrogen chloride). The combination of rare gas and halogen determines the output wavelength. Available wavelengths include:

$\begin{array}{ll}\text { ArF } & 193 \mathrm{~nm} \\ \mathrm{KrF} & 248 \mathrm{~nm} \\ \mathrm{XeCl} & 308 \mathrm{~nm} \\ \mathrm{XeF} & 351 \mathrm{~nm}\end{array}$

A further laser action arises from the molecular fluorine transition $\left(F_{2}\right)$ although the output of this gas mix is weaker than any other. Typical outputs are pulse energies of a few hundred milliJoules to one Joule, and repetition rates of ten $\mathrm{Hz}$ to a few hundred $\mathrm{Hz}$, although for specialised lasers $1000 \mathrm{~Hz}$ is available now

The average power is in the range of $10 \mathrm{~W}$ to one $\mathrm{kW}$. The pulse length is short, typical in the $10-20 \mathrm{~ns}$ range. This results in peak powers of tens of megawatts. The short wavelength also provides high-resolution imaging. These and other unique properties of UV light have provided a broad field of applications. The different lasers offer a variety of photon energies, which can be selected to match the requirements of a given application (Table 5.1).

Galantucci [39] has developed a 3D numerical model for excimer laser cutting. The results are in agreement with experimental results as obtained for polyester ablation rates of $0.8 \mu \mathrm{m} /$ pulse for $1 \mathrm{~J} / \mathrm{cm}^{2}$ to $1.4 \mu \mathrm{m} /$ pulse for 15 $\mathrm{J} / \mathrm{cm}^{2}(248 \mathrm{~nm}, 10-100 \mathrm{~Hz})$. Excimer lasers are mostly applied using mask projection set-up allowing $3-10$ times reduction rates (Figure 5.1 )

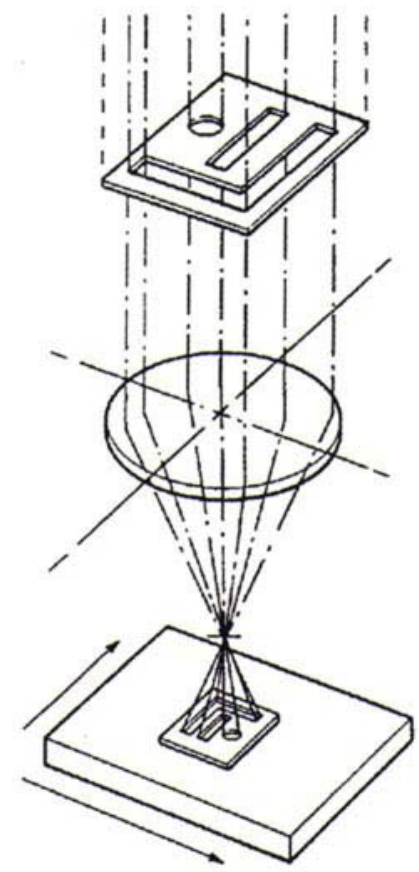

Figure 5.1. A laser beam with uniform beam profile is projected by a mask on a micro part.

Table 5.1. Photon energies obtained from different laser sources [38].

\begin{tabular}{|c|c|c|}
\hline Laser & Wavelength $(\mathrm{nm})$ & Photon energy $(\mathrm{eV})$ \\
\hline $\mathrm{XeF}$ & 351 & 3.53 \\
$\mathrm{XeCl}$ & 308 & 4.03 \\
$\mathrm{KrF}$ & 248 & 5.00 \\
$\mathrm{KrCl}$ & 222 & 5.50 \\
$\mathrm{ArF}$ & 193 & 6.42 \\
$\mathrm{~F}_{2}$ & 157 & 7.43 \\
\hline
\end{tabular}

\subsection{Some details about the laser}

Excimer is an acronym for excited dimer, a rare gas halogen like ArF molecules. Such molecules have a very short lifetime, existing in the exited state. Excimer molecules are produced by electron excitation in a gas mixture of fluorine or chlorine, a buffer gas like helium and a rare gas $(\mathrm{Ar}, \mathrm{Kr}$ or $\mathrm{Xe}$ ). Excited dimers are produced by a high voltage discharge pulse. The reaction starts with electron attachment to the fluorine molecule, followed by a two-step ionisation of the rare gas, then three-body excimer formation and finally spontaneous and stimulated emission

$\begin{array}{ll}\mathrm{F}_{2}+\mathrm{e} \rightarrow \mathrm{F}^{-}+\mathrm{F} & \text { excitation } \\ \mathrm{Kr}+\mathrm{e} \rightarrow \mathrm{Kr}^{\star}+\mathrm{e} & 2 \text { step } \\ \mathrm{Kr}^{\star}+\mathrm{e} \rightarrow \mathrm{Kr}^{+}+2 \mathrm{e} & \text { ionisation } \\ \mathrm{Kr}^{+}+\mathrm{F}^{-}+\mathrm{He} \rightarrow \mathrm{KrF}^{\star}+\mathrm{He} & \text { excimer formation } \\ \mathrm{KrF}^{\star} \rightarrow \mathrm{Kr}+\mathrm{F}+\mathrm{hv} & \text { Laser action } \\ \mathrm{F}+\mathrm{F}+\mathrm{He} \rightarrow \mathrm{F}_{2}+\mathrm{He} & \text { slow }\end{array}$

Figure 5.2. Primary reactions producing excimer radiation ( $\mathrm{Kr}^{\star}$ denotes an excited $\mathrm{Kr}$ atom). [40] 
Excimer lasers require high power density discharge to produce sufficiently high populations of excited molecules for laser action. This is obtained by a fast transverse electrical discharge in a pre-ionised gas. The materials that come in contact with the gas mixture need to be extremely inert because molecular fluorine is highly reactive, corrosive and toxic. By products of corrosion will absorb laser energy, deposit particles on the output optics so laser gas purity must be very high.

Proper laser gas handling systems and maintenance are required to ensure safe, uninterrupted operation of the system. Based on the application different designs of the laser cavity are applied. A top-hat like profile of ca $1 \times 2$ $\mathrm{cm}$ is required for mask projection applications (Figure 5.1) while for high quality processes and for deep hole drilling, where the beam is directly focused in the material, a preferably a nearly $\mathrm{TEM}_{00}$ mode is generated.

\subsection{Applications}

The application areas of excimer lasers are

$$
\begin{aligned}
& \text { Ablation } \\
& \text { Lithography } \\
& \text { Micro fabrication }
\end{aligned}
$$$$
\text { - Others }
$$

Ablation

The term ablation describes the effect of vaporizing material, which is irradiated by the laser beam. Generally two mechanisms are distinguished: photolitic and pyrolitic processes. In photolitic processes the photon energy is directly applied to overcome the chemical bonding energy of (macro) molecules. In case of polymers they are broken in smaller (often gaseous) monomers. For most ablation processes the photon energy of the 248 $\mathrm{nm} \mathrm{KrF} \mathrm{laser} \mathrm{is} \mathrm{sufficient} \mathrm{as} \mathrm{shown} \mathrm{in} \mathrm{Table} \mathrm{5.1} \mathrm{and} \mathrm{5.2.}$

Table 5.2. Chemical bonding energies:

\begin{tabular}{|c|c|}
\hline Chemical bond & Bond energy $(\mathrm{eV})$ \\
\hline $\mathrm{Si}-\mathrm{Si}, \mathrm{Cl}-\mathrm{Cl}$ & $1.8-3$ \\
$\mathrm{C}-\mathrm{N}, \mathrm{C}-\mathrm{C}$ & $3-3.5$ \\
$\mathrm{C}-\mathrm{H}, \mathrm{O}-\mathrm{H}$ & $4.5-4.9$ \\
$\mathrm{C}=\mathrm{C}$ & 7 \\
\hline
\end{tabular}

In the ideal case all laser energy is used to overcome the chemical binding energy. Such processes are known as "cold ablation". In case of metals however the laser energy is first absorbed by electrons, then transferred to heat which melts and evaporates the metal, just like other lasers do. Figure 5.3 shows clearly how in photolitic processes "the molecules are taken away", while pyrolitic processes melts the material first and evaporates from the melt surface.

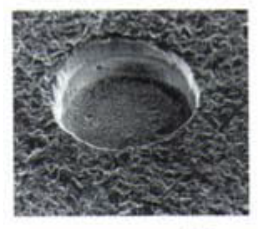

$100 \mathrm{~mm}$

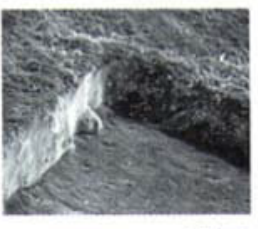

$100 \mu \mathrm{m}$

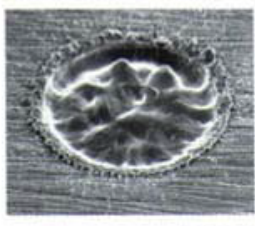

$100 \mu \mathrm{m}$
Figure 5.3: Interaction of excimer laser radiation with solids. Right: PVC, photolitic ablation. Left: metal, melt. Middle: $\mathrm{Al}_{2} \mathrm{O}_{3}$ ceramic, combined photolitic and pyrolitic process. Lambda Physik [41]

The material removal of organic polymers consists of three steps. First the UV photons are absorbed in the top layer of typical $0.2 \mu \mathrm{m}$ thickness, then the long chain molecules in this layer are broken into parts and finally they are removed from the processing area in the form of vapour and small particles. Photons with more than 5.1 $\mathrm{eV}$ will break apart oxygen molecules in its path. This is demonstrated by the characteristic ozone smell of a 193 $\mathrm{nm}$ ArF beam passing through air.

The threshold fluence for a wide variety of plastics is about $120 \mathrm{~mJ} / \mathrm{cm}^{2}$. At low fluence the walls become tapered from about $2^{\circ}$ at $500 \mathrm{~mJ} / \mathrm{cm}^{2}$ to $20^{\circ}$ at 150 $\mathrm{mJ} / \mathrm{cm}^{2}$. Useful fluences are given in Table 5.3 and 5.4

Table 5.3. Ablation thresholds for various materials

\begin{tabular}{|l|c|}
\hline Material & Fluency, $\mathrm{mJ} / \mathrm{cm}^{2}$ \\
\hline Photo resist & 30 \\
Polycarbonate & 40 \\
Polyimide & 45 \\
Silicon nitride & 195 \\
$\mathrm{SiO}_{2}$ & 350 \\
Glass, metal oxide & $700-1200$ \\
Metals & $4000-8000$ \\
\hline
\end{tabular}

Table 5.4. Parameters for drilling $100 \mu \mathrm{m}$ holes.

\begin{tabular}{|c|c|c|}
\hline Material & $\begin{array}{c}\text { Fluence } \\
\mathrm{J} / \mathrm{cm}^{2}\end{array}$ & $\begin{array}{c}\text { Ablation rate } \\
(\mu \mathrm{m} / \text { pulse })\end{array}$ \\
\hline Polycarbonate & 4 & 0.4 \\
Polyester & 4 & 0.8 \\
Polyethylene & 3.7 & 1.0 \\
Silicone rubber & 10 & 1.5 \\
Kapton foil & 10 & 1.2 \\
Plexiglas & 1 & 0.3 \\
Hostaform & 2.8 & 0.6 \\
\hline
\end{tabular}

\section{Lithography}

Lithography plays a vital role in microelectronics. The cost of lithography is typical $35-40 \%$ of the wafer costs. Currently mostly the $248 \mathrm{~nm} \mathrm{KrF}$ laser is applied in step and repeat cameras. Based upon trends over the last 20 years [42] it is likely that $64 \mathrm{~Gb}$ DRAMS with $70 \mathrm{~nm}$ features will be in production in 2009. This requires shorter wavelengths of $193 \mathrm{~nm}$ and further $157 \mathrm{~nm}$. This requires the development of high performance deep-UV optical components from materials like $\mathrm{BaF}_{2}$ or $\mathrm{CaF}_{2}$ which have to be developed under an tight time schedule for the introduction of $157 \mathrm{~nm}$ that the industry is committed to achieve [43].

\section{Laser LIGA}

Excimer laser ablation is also used for the fabrication of micro electro mechanical systems (MEMS) by the LIGA process. As an alternative for the expensive X-ray LIGA the laser-LIGA process has been developed for the realisation of three-dimensional microstructures [44]. This process produces nickel structures of several hundredmicrometer thicknesses. By alternating deposition of metal and resin layers complex multiplayer structures can be obtained by excimer mask projection ablation [45].

\section{Micro fabrication}

Micro parts of almost any geometry can be produced by mask projection. Drilling holes, however, is the key application in micro fabrication. Excimer lasers offer three significant advantages for drilling applications over lasers that emit in the visible and infrared. First, the short ultraviolet light can be imaged to a smaller spot size than the longer wavelengths. This is because the minimum feature size is limited by diffraction, which depends 
linearly with the wavelength. The second advantage is that due to the mechanism of "photoablation" there is less thermal influence or melting of the surrounding material. Finally, most materials have high absorption in the ultraviolet region. This means that the penetration depth is small and each pulse removes only a thin layer of material, allowing precise control of the drilling depth [46].

In printed circuit board (PCB) fabrication many bridging holes (via's) are produced to make electrical connections in multiplayer PCBs. The holes are drilled in dielectric polyimide layer until the underlying copper layer is uncovered. The drilling then stops automatically because of the higher threshold (one order of magnitude) of copper. The conducting connection is made by a following chemical deposition of copper on the via walls. The process has been developed in 1990 by Bachmann [47] and is used for drilling small $\approx 10 \mu \mathrm{m}$ holes. However, for bigger holes of $100 \mu \mathrm{m}$ and above the cheaper and faster $\mathrm{CO}_{2}$ lasers are currently used

\section{Ink jet nozzles}

Ink jet printers are widely used because they offer good quality at low cost, based on a simple design. It consist of an array of small orifices with precisely defined diameter and taper, each located on top of a channel with resister heater. Small bubbles are formed when the ink is heated ejecting small ( 3 - 80 picoliters) drops out of the nozzle. Riccardi [48] describes the fabrication of high-resolution bubble ink jet nozzles, Figure 5.4. Depending on the design up to 300 holes have to be drilled simultaneously in a $0.5 \times 15 \mathrm{~mm}$ area. This is obtained by $5 \times$ demagnification of a $400 \mathrm{~mJ}$ pulse to 0.6 to $0.8 \mathrm{~J} / \mathrm{cm}^{2}$ fluency. Ca. 300 pulses are applied to obtain $55 \mu \mathrm{m}$ holes with $27^{\circ}$ taper. The total drilling time is about one second using a $300 \mathrm{~Hz} \mathrm{KrF}$ laser. Recent developments will require smaller holes below $25 \mu \mathrm{m}$ diameter.

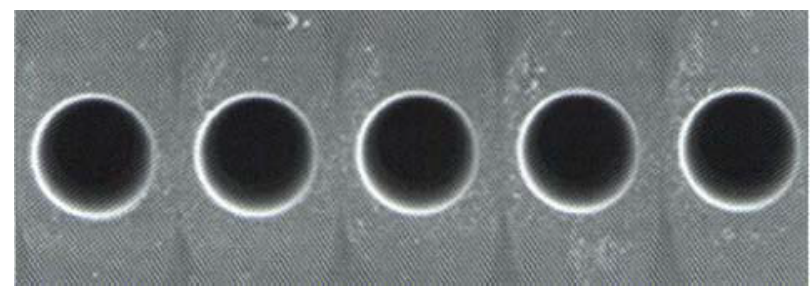

Figure 5.4. Array of ink jet nozzles drilled in $50 \mu \mathrm{m}$ thick polyimide.

\section{Others}

There are a lot of other applications of short pulsed excimer lasers like marking of eye glasses, medical devices, aircraft cables and electronic devices, writing of fiber Bragg gratings for telecom applications, medical applications in surgery etc. Two of them will be described in more detail, ablation of diamond and laser cleaning.

Laser ablation of diamond

Diamond is difficult to machine [49] because it is transparent in a wide range of wavelength. At high power densities, however, the diamond is transited into graphite, which absorbs the laser power and is removed by ablation subsequently. Diamond machining is currently done by micro-second pulse Nd:YAG and nano-second pulse excimer lasers [50].

Examples of applications are drilling holes in wire drawing dies (Figure 5.5) and cutting of knife blades for eye surgery. Thin layers of graphite or amorphous carbon are found on the surface after laser machining which requires an extra polishing operation to remove the graphite. An alternative (new) technique is the use of ultrashort femtosecond lasers. No evidence of graphite was found [51] because the thermal diffusion depth is only $50 \mathrm{~nm}$. Some processing data is given in Table 5.5

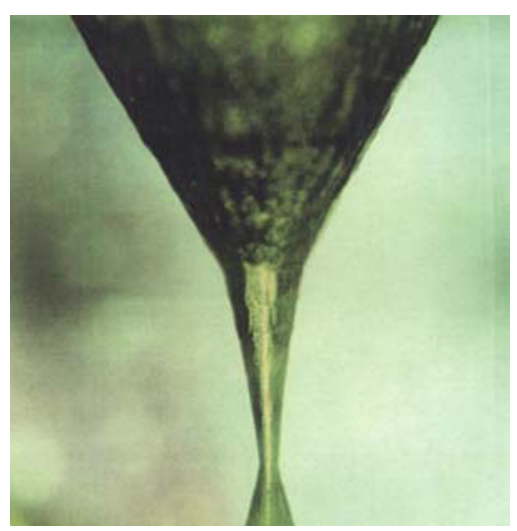

Figure 5.5. Diamond wire drawing die. Wire opening $50 \mu \mathrm{m}$. Photo: Diamond Tools Group. Netherlands.

Table 5.5. Laser ablation of diamond

\begin{tabular}{|c|c|c|c|}
\hline Laser & $\begin{array}{l}\text { Q-switched } \\
\text { Nd:YAG }\end{array}$ & \begin{tabular}{|l} 
Excimer \\
laser
\end{tabular} & \begin{tabular}{|l} 
Femto- \\
second laser
\end{tabular} \\
\hline Wavelength & $1.06 \mu \mathrm{m}$ & $248 \mathrm{~nm}$ & $248 \mathrm{~nm}$ \\
\hline Pulse length & $150 \mathrm{~ns}$ & $20 \mathrm{~ns}$ & $500 \mathrm{fs}$ \\
\hline Diffusion depth & $30 \mu \mathrm{m}$ & $10 \mu \mathrm{m}$ & $50 \mathrm{~nm}$ \\
\hline Fluence $\left(\mathrm{J} / \mathrm{cm}^{2}\right)$ & \multicolumn{3}{|c|}{ Removal rates per pulse } \\
\hline 0.8 & & $5 \mathrm{~nm}$ & $5 \mathrm{~nm}$ \\
\hline 2 & & $10 \mathrm{~nm}$ & $15 \mathrm{~nm}$ \\
\hline 4 & & $20 \mathrm{~nm}$ & $35 \mathrm{~nm}$ \\
\hline 6 & & $30 \mathrm{~nm}$ & $50 \mathrm{~nm}$ \\
\hline 10 & $0.5 \mu \mathrm{m}$ & $45 \mathrm{~nm}$ & \\
\hline 20 & $1.0 \mu \mathrm{m}$ & $60 \mathrm{~nm}$ & \\
\hline 50 & $2.5 \mu \mathrm{m}$ & & \\
\hline 150 & $4.0 \mu \mathrm{m}$ & & \\
\hline
\end{tabular}

\section{Excimer laser cleaning}

Q-switched Nd:YAG lasers as well as excimer lasers are applied for surface cleaning, particularly in the electronic industry. Examples are cleaning of silicon stencils (masks for e-beam lithography), magnetic head sliders and optical components. Particles are preferably removed using a thin liquid film of water or ethanol allowing low energy densities for an explosive evaporation of the liquid, which blows away all particles. Differences in ablation threshold are used to remove printing residues from chromium plated rotogravure cylinders. By scanning the whole surface at a fluency below the ablation threshold for the chromium $(\approx 5 \mathrm{~J} / \mathrm{cm} 2)$ all contamination is removed in an environmental friendly way [52].

\section{Surface cleaning of Art}

Impressing results were achieved in the restoration of paintings, which were previously treated unsuccessfully by conventional methods, by $20 \mathrm{~ns} \mathrm{KrF}$ excimer laser pulses (Figure 5.6). The ablation depth per pulse is about $1 \mu \mathrm{m}$. Process monitoring of the laser induced plasma by real time spectroscopy [53] allows for precise control of the ablation depth and identification of the different layers. 

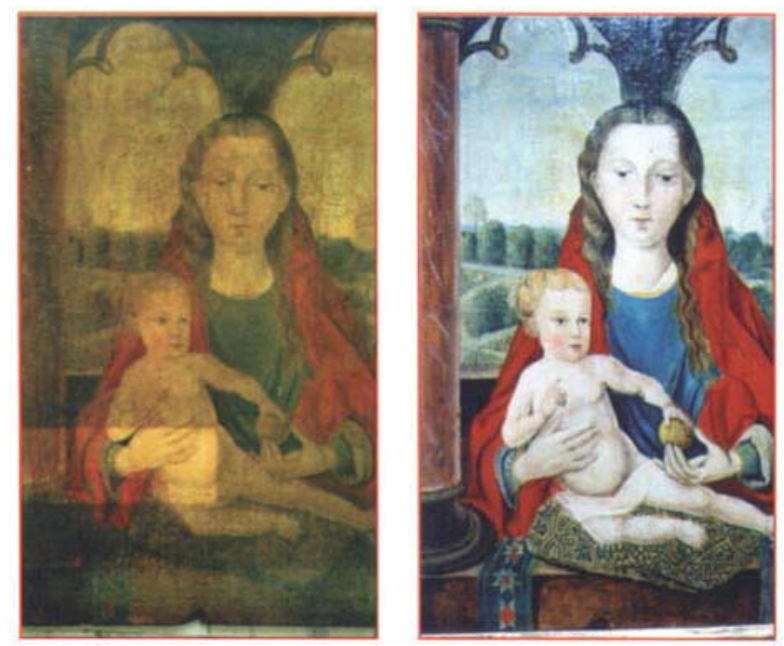

Figure 5.6. Partial laser cleaned (left) and fully cleaned fine arts. Courtesy Art-Innovation, Hengelo NL [54].

\subsection{Future developments}

New lasers

The market forecast for excimer lasers is more or less stable. At the low power segment there is a shift from excimer lasers toward the new higher harmonic Nd:YAG lasers (green $532 \mathrm{~nm}$ and UV 355 or $266 \mathrm{~nm}$ ), which become available for low power micromachining and for semiconductor materials processing. The UV Nd:YAG lasers operate in the same wavelength and pulse length domain as the excimer laser. The average output is one to two orders less, but nevertheless the peak power intensity is high $\left(10^{7}-10^{8} \mathrm{~W} / \mathrm{cm}^{2}\right)$ because of the short pulse length and superior beam quality. An example of what can be realised is given in Figure 5.7.

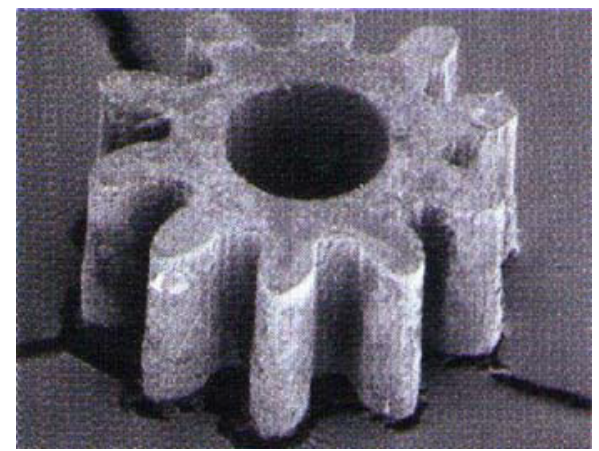

Figure 5.7. A $0.25 \mathrm{~mm}$ thick sapphire gear wheel used in a fluid sensor made by multi passes $355 \mathrm{~nm}$ laser pulses for high precision and no microcracking. (LZH)

Another development are the very high power $\mathrm{kW}$ excimer lasers, which are developed for simultaneous drilling for huge amounts of small holes for instance for the aerospace industry (holes for cooling of engine parts and for boundary layer suction). One of the research efforts in this area is the generation of longer pulses [55]. The driving force is an increased overall system efficiency, lower stresses on the electrical components and better beam quality. Longer pulses could also be more efficiently transmitted in fiber delivery systems [56].

\section{Nano particles}

Nanoparticles are interesting for future applications as nano composites, as devices such as biological sensors, as basis for novel LEDs or to be used as thick film silver nanoparticles paste for electronic devices. Nanometer size particles are currently grown through vapour condensation or flame spray techniques, but all suffer from inefficiency, impurities or complexity. Laser based techniques may lead to the industrial production of nanoparticles without any of these limitations. The idea is to produce nanoparticles by illuminating a stream of microparticles with a pulsed excimer laser. Research at the University of Texas and DuPont Electronic Materials [57] has shown the feasibility to ablate a low velocity aerosol stream of 2 um diameter microparticles with 10 ns pulses from a $249 \mathrm{~nm} \mathrm{KrF}$ laser. It results in nucleation of nanoparticles, which are unagglomerated and relatively uniform in size. The output should be scaled up considerably to meet the industrial needs. It is expected that this can be realized when new developed $\mathrm{kW}$ excimer lasers break through on the market.

\section{D Micromachining}

With normal mask projection techniques the homogeneous power density distribution will result in an equal ablation over the whole area of the mask. For 3D structures different sets of mask are used. This generally results in a stepwise structure. Masuzawa [58] has developed the Hole Area Modulation method using a semitransparent mask, consisting of series of small holes enabling a continuous variable depth just by oscillating the mask in pre-programmed patterns.

\section{COPPER VAPOR LASERS}

Copper vapor lasers (CVL) belong to the family of metal vapor lasers, which use mixtures of metal vapor and rare gases to produce laser light. There are copper vapor, helium-cadmium and gold vapor lasers. They operate at temperatures of $200-1200 \mathrm{C}$ to keep the metal in vapor state. The excitation is by electrical discharges in the gas mixture.

\subsection{The laser}

Copper vapor lasers produce green and yellow light from a mixture of copper vapor and helium or neon. They are excellent sources of short, high intensity laser pulses at high repetition rate.

The active medium, copper, is contained in a ceramic tube $1 \mathrm{~m}$ length, $25 \mathrm{~mm}$ diameter for $20 \mathrm{~W}$ output and up to $3 \mathrm{~m} \mathrm{x} 60 \mathrm{~mm}$ for $300 \mathrm{~W}$ and more. The tube is contained in a vacuum envelope and heated by a pulsed discharge to $1450^{\circ} \mathrm{C}$ where the copper vaporises. Laser action results from high-energy electrons and neutral copper atoms. The neon at a pressure of 20 to $60 \mathrm{mbar}$ starts the discharge current when the tube is cold.

The overall ('wall-plug') efficiency of $1 \%$ is much better than $\mathrm{HeNe}$ or argon lasers. Commercial copper lasers produce up to $120 \mathrm{~W}$ average output power. Wavelength 510.6 (green) and $578.2 \mathrm{~nm}$ (yellow), pulse repetition frequency over excess of $30 \mathrm{kHz}$, pulse duration 20-50 ns, peak power up to $100 \mathrm{~kW}$. For scientific lasers, Lawrence Livermore National Laboratory has reported output powers of more than $800 \mathrm{~W}$.

The light of copper vapor lasers can also be frequency doubled $255 \mathrm{~nm}$ (second harmonic green) or $289 \mathrm{~nm}$ (second harmonic yellow). Typical average power is $1 \mathrm{~W}$ at $5 \mathrm{kHz}$. These lasers might be an alternative to excimer lasers although the pulse energies are considerably less $(0.2 \mathrm{~mJ})$ than excimer lasers, but they have a good spatial coherence and a low divergence. This means that even with low pulse energy the fluences necessary for machining $\left(0.1\right.$ to $\left.20 \mathrm{~J} / \mathrm{cm}^{2}\right)$ can easily be provided [59]. The removal rates are similar to that obtained by an excimer laser at $0.3 \mu \mathrm{m}$ per pulse for kapton. The advantage however is the repetition frequency, which is a factor of 20 higher as those obtained using excimer lasers operating at $250 \mathrm{~Hz}$ and $1 \mathrm{~J} / \mathrm{cm}^{2}$. Working with UV copper vapor lasers requires relatively expensive UV optics, which are prone to degradation. The main problem encountered with frequency-doubled systems is 
the degradation to the faces of the doubling crystal with time. Crystal faces must be repolished after approximately 500 hours. However, most of the beam management is carried out in the visible area using relatively inexpensive optics.

\subsection{Examples of applications}

Copper vapor lasers are mainly applied to drill, cut and micro mill materials with a thickness up to $1.5 \mathrm{~mm}$ in Metals, Silicon, Diamond, Ceramics and Polymers

Typical applications are:

- Inkjet nozzle drilling

- Diesel injector drilling

- $\quad$ Spinneret drilling and cutting

- Precision machining development

- Writing Fiber Bragg Gratings

Drilling, cutting and micro milling are the common applications for the green light [60]. Among them simple "holes" remain the most popular micro machined structures. These are found in medical flow controllers, microelectronic contacts and medical filters (Figure 6.1). Holes are also used to make plastics "breathable", to calibrate leak testers and to perforate foils.

The light of copper vapor lasers is more strongly absorbed in metals than that of IR lasers. This leads to deep holes with a small heat affected zone. Aspect ratios of greater than 40 and surface roughness in the order of 1-2 $\mu \mathrm{m}$ are reported by Allen [61]. The high speed is utilized best if the machine is equipped with a trepanning and a galvo machining head. $\mathrm{CNC}$ workstations are now being developed and coming on the market. Some examples of machining data:

- Cutting of $150 \mu \mathrm{m}$ thick metal foils at $15 \mathrm{~mm} / \mathrm{s}$.

- Cutting of $500 \mu \mathrm{m}$ thick foil at $0.5 \mathrm{~mm} / \mathrm{s}$.

- Cutting of silicon wafer and solar cells at 0.5 to $1 \mathrm{~mm} / \mathrm{s}$

- Drilling high quality holes in PE 15 to $250 \mu \mathrm{m}$ diameters in about $100 \mathrm{~ms}$

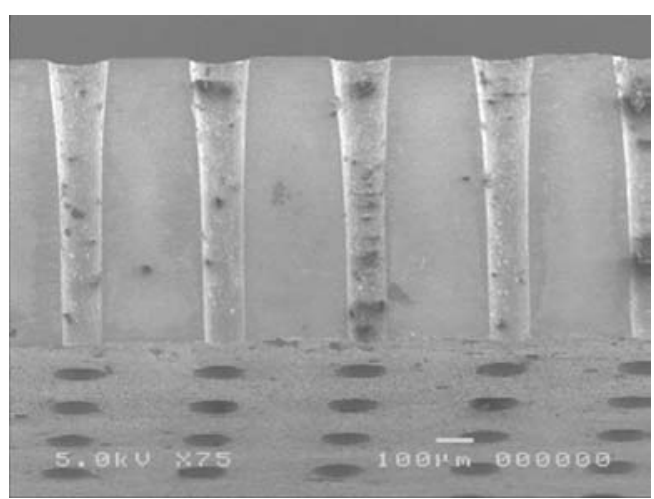

Figure 6.1. Array of $100 \mu \mathrm{m}$ holes for medical filters.

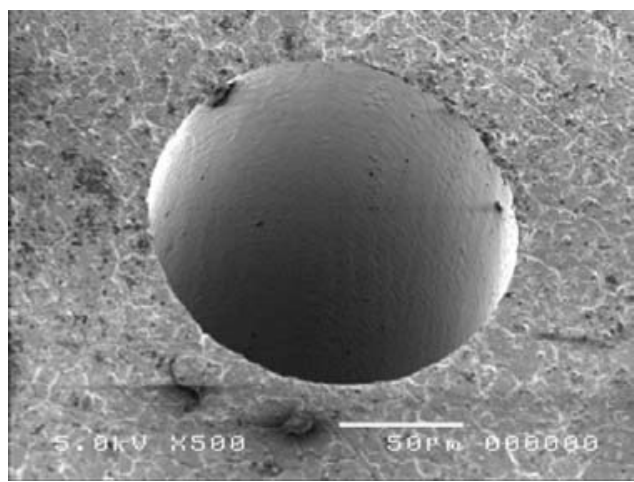

Figure 6.2. Close up of one hole from array
In the automotive sector engineers are under considerably regulatory pressure to reduce the emission level of combustion engines. A major contributor to high emissions is the fuel injector design. The current technique of EDM produces excellent holes but suffers from low processing speed. Hole diameters less than 150 $\mu \mathrm{m}$ become increasingly difficult. Micromachining by $\mathrm{CVL}$ has demonstrated the ability to produce nozzles with diameters of $50-200 \mu \mathrm{m}$ with no dross on the exit side. The entry side has minimum dross, which can be removed by light abrasion. Figure 6.4 shows some $50 \mu \mathrm{m}$ holes.

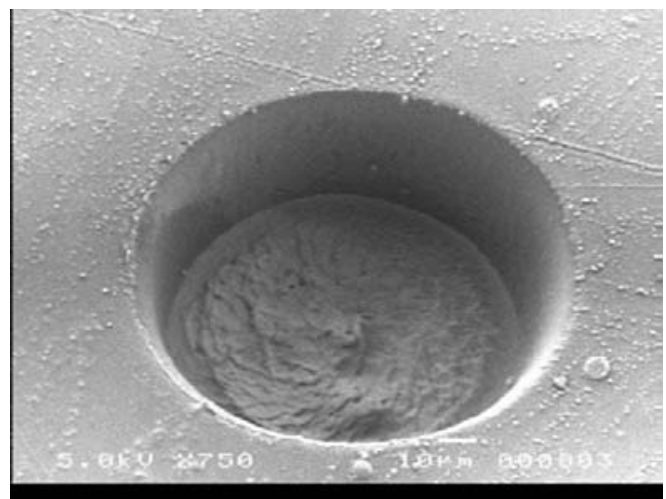

Figure 6.3. Example of a blind hole

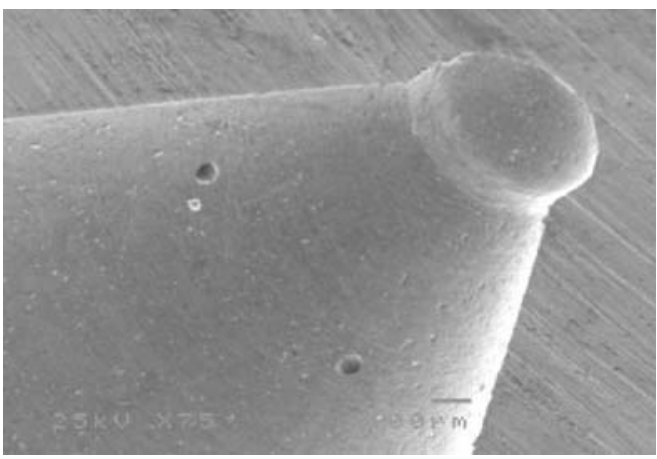

Figure 6.4. Section of diesel injection nozzle.

Progress in drug discovery and analysis of the human genome sequence require the development of micro tools and techniques to acquire and process vast amounts of data looking at the behaviour of many thousands of genes together. This corresponds with increased speed and automation in biomedical instrumentation like a pin based picolitre dispenser to take thousands of genetic samples for massive parallel testing. The critical component is a tapered pin with a capillary slot. Elmes et al [62] conclude that laser micro machining is the preferred technique (Figure 6.5).

\section{Fabrication of ink jet nozzles}

Ink jet nozzles require accurate dimensions and smooth surface finish to obtain laminar flow of ink and prevent turbulence. Allen [63] has fabricated ink jet nozzles of metal sheet by three different fabrication techniques (micro-electrodischarge machining, micro drilling and CVL machining) and evaluated the characteristics of each technique while assessing the differences between them

Micro EDM is one of the few techniques that can be used for micro hole fabrication following Almond [64] and Masuzawa [65]. A single hole of $50 \mu \mathrm{m}$ diameter through $100 \mu \mathrm{m}$ thick stainless steel takes typical 3 minutes. With CVL a single pulse will remove the material to a depth of $10 \mu \mathrm{m}$, which means that microholes are machined within seconds by $30 \mathrm{~ns}$ pulses at $10 \mathrm{kHz}$. The short pulsewidth 
in CVL reduces the Heat Affected Zone. Aspect ratios of greater than 40 are reported for stainless steel, the surface roughness is of the order of 1 to $2 \mu \mathrm{m}$. Trepanning was used to improve the quality of the holes. Results are given in Table 6.1.

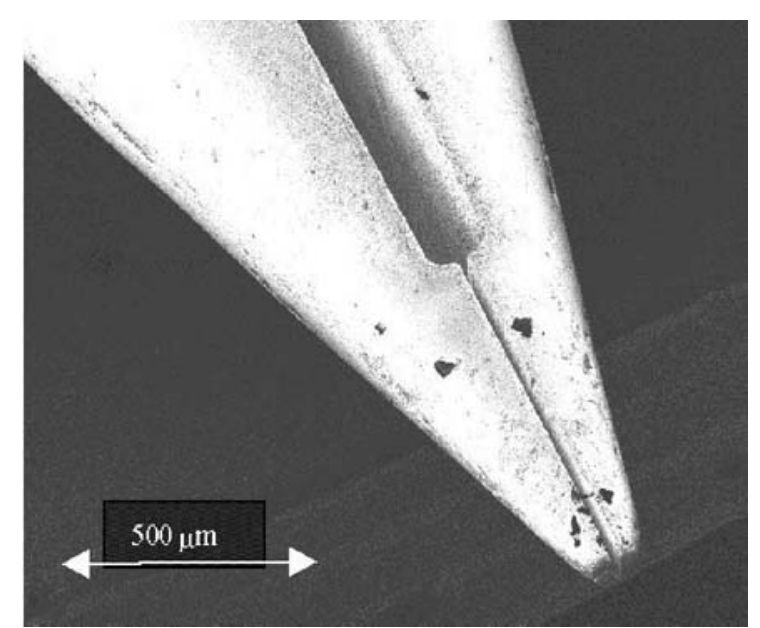

Figure 6.5. SEM micrograph of a micro reservoir pin with a capillary slot $15 \mu \mathrm{m}$ wide by $600 \mu \mathrm{m}$ long and a reservoir $100 \mu \mathrm{m}$ wide and $1000 \mu \mathrm{m}$ long cut by a CVL. (M. Knowles [62])

Table 6.1. Comparison of microhole fabrication methods.

\begin{tabular}{|l|l|l|}
\hline Process & Advantages & Disadvantages \\
\hline Micro-EDM & $\begin{array}{l}\text { Surface finish, } \\
\text { edge profile }\end{array}$ & Slow \\
\hline CVL & $\begin{array}{l}\text { Edge profile, } \\
\text { Fast }\end{array}$ & $\begin{array}{l}\text { Flaked recast gives } \\
\text { rougher appearance }\end{array}$ \\
\hline Micro drilling & Fast & $\begin{array}{l}\text { Burring of edges, } \\
\text { tool breakage }\end{array}$ \\
\hline
\end{tabular}

Although micro-EDM is an established process with excellent hole quality, its relative slowness is its main drawback. CVL is much faster but the improvement of surface profile requires further investigation.

\subsection{Economic considerations}

Industry is beginning to realize how laser micromachining can fulfil its potential need for more complicated structures. A greater demand for the complex nonrepetitive micro patterning of materials makes masking techniques expensive and time consuming. In those cases the direct write micro pattern generation of UV copper vapor lasers makes them an alternative to excimer lasers. Direct writing of complex microstructures is applied in creating channels in glass plates to control micro fluid flow, engraving hard materials, micro marking for security purposes etc. The operation cost is estimated as $\$ 8$ per hour [59] resulting in 1 Scent per hole.

\subsection{Future developments}

High precision micromachining will be the key application that finally will cause the industrial breakthrough of copper vapour lasers. A new development is the copper hybrid source. The hydrogen bromide will reduce the operating temperature to $600-800{ }^{\circ} \mathrm{C}$. resulting in efficiencies of 2 to $3 \%$ and a superior beam quality [66]. Problems still to be solved in future deal with the toxicity of hydrogen bromide.

\section{FEMTO SECOND LASERS}

The newest generation pulsed lasers delivering the shortest pulses are the femto second lasers. In these systems, pulsing is mostly achieved by mode coupling of a broadband laser source. Typically, the bandwidth exceeds several tens of $\mathrm{nm}$ bandwidth, which allows pulse duration well below 100 fs. Due to the short pulse duration, peak powers of more than $15 \mathrm{GW}$ can be reached, which gives access to further ablation mechanisms, like multi photon ionisation (MPI)

\subsection{Introduction and application field}

Due to the short interaction time only the electrons within the material are heated during the pulse duration. Once the laser pulse has stopped, the lattice of the material experiences the influence of the overheated electrons. This results in two different ablation regimes, dependent on the penetration depth of the overheated electrons, which can exceed the optical penetration depth. This is shown in Figure 7.1.

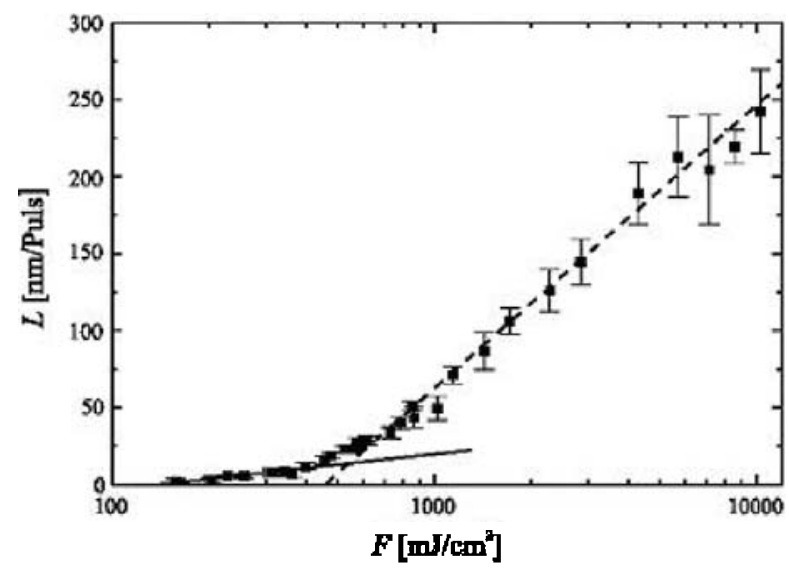

Figure.7.1. Ablation rates in Copper by S. Nolte [67].

Especially for low fluences, where the thermal diffusion length is smaller than the optical penetration depth, heat diffusion can be strongly suppressed, which allow highest precision and minimal heat influence within the material. Furthermore, the intensity during the laser pulses is high enough to initiate multi-photon effects, which allows machining of literally any solid material.

Due to the limited average power output of present fs laser systems, applications are up to now limited to micro-machining processes, where the total volume of ablated material is rather small. Further applications can be located in metrology, where the bandwidth of the laser is advantageous, e.g. in optical coherence tomography (OCT).

\subsection{Some details about the laser}

Presently, most fs lasers are based on titanium:sapphire, due to its broad bandwidth. The short pulses are generated within the oscillator, typically providing a pulse train of short pulses at low pulse energy of some $\mathrm{nJ}$ per pulse. As this energy is not sufficient for most micromachining applications, further amplification has to be provided. A direct amplification is not viable, as the intensity would rise beyond values, where destruction of beam profiles and later the internal optics would occur. Therefore, the intensity has to be reduced to sufficient values, which is being done using the chirped pulse amplification technique (CPA)].

Using CPA technique, the different spectral parts of the laser bandwidth are spread locally by means of prisms or 
gratings. Providing a set-up where the shorter wavelengths propagate a shorter path than the longer ones, the pulse can be stretched in time, thus reducing the intensity sufficiently low. After the amplification of single pulses, the original pulse duration can almost be reached by compressing the pulse using a similar set-up as applied in the stretcher, but with reversed propagation paths [68]. Typical commercial available systems show average output powers of $1.5 \mathrm{~W}$ and up to $5 \mathrm{kHz}$ repetition rate. This power output allows micro-machining processes, but sets limits regarding the amount of removed material per time. Nevertheless, promising applications can be found in the precise machining of thermal sensitive materials.

\subsection{Examples of applications}

Apart from direct use of fs-lasers in medicine for surgery, for example the correction of myopia like LASIK (laser assisted in situ keratomileusis) [69], the structuring of medical implants, e.g. coronary stents, is a promising application with growing industrial interest [70]. Coronary stents are used as an minimally invasive treatment of arteriosclerosis, as an alternative for bypass operations. Since the requirements of medical implants (e.g. burrfreeness, x-ray opacity) are very strict, just a few materials are commonly used. Today, typical materials used for stents are stainless steel or shape memory alloys. For these materials chemical post-processing techniques have been developed to achieve the required properties. However, these materials are not optimal in several medical aspects (e.g. risk of restenosis, limited bio-compatibility etc.). New approaches favour stents for temporary use only, which necessitate bioresorbable materials like special bio-polymers (Figure 7.2a).

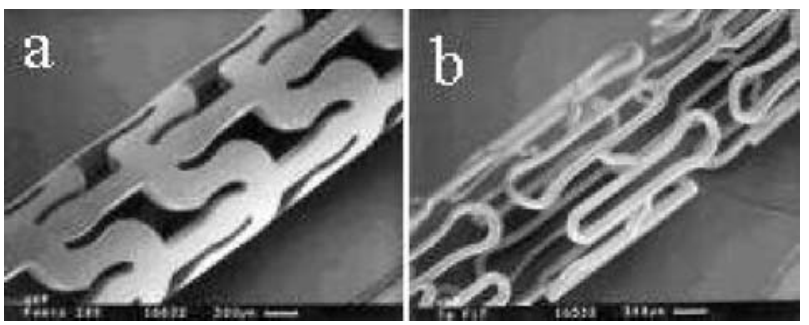

Figure 7.2. Prototypes of stents made of: (a) bioresorbable polymer, (b) tantalum

Other materials, like tantalum, show improved $\mathrm{x}$-ray visibility (Figure 7.2b). For these materials, no established post-processing technique is available. Furthermore, most of them show strong reactions to thermal load. Therefore, it is essential to avoid influences on the remaining material in order to keep the specific material properties. Femtosecond pulse laser material processing meets the requirements of these materials.

\section{Acceleration grids used for streak camera tubes}

The machining of metallic structures in the micrometer range can be performed successfully using fs-laser pulses. A promising application is the machining of acceleration grids, to be used in streak camera tubes as shown in Figure 7.3. Acceleration grids must be highly transmitting for electrons, and still have to generate an electric field as homogeneous as possible. This is fulfilled by generating grids with many thin struts. However, these fine struts are likely to be deformed by mechanical or thermal stress during fabrication.

Using ultrashort laser pulses results despite of the small structural size in deformation free grids with no burrs. The achieved transmission ratio of the grids is about 60 $\%$. Presently, acceleration meshes are manufactured by lithographic and electro-forming techniques. Although this technique allows to machine very sharp geometries at reasonably low costs, it is economical only for massproduction. Furthermore, it is not possible to create flank angles using lithographic methods, which is an important requirement for dynode structures. Here, femtosecond machining offers new ways for machining such structures.
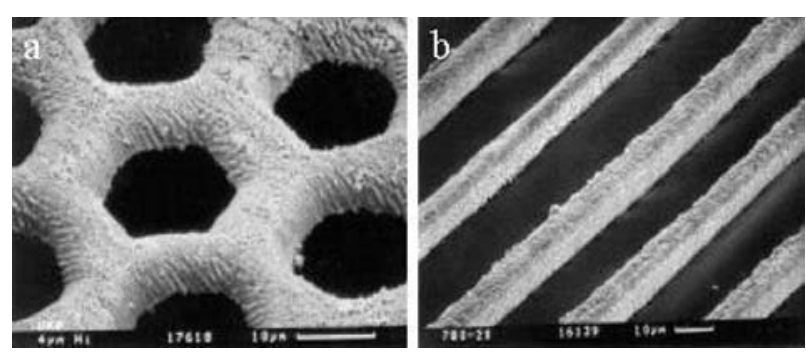

Figure 7.3. Femtosecond machined acceleration meshes (a) Hexagonal mesh with structural periodicity of $20 \mu \mathrm{m}$, (b) grid mesh. Overall structure size of both meshes: $11 \times 8 \mathrm{~mm}^{2}$

\section{Cutting of silicon}

Silicon is the most important material in the micro and semiconductor industry. It is most frequently used for the fabrication of microchips, sensors, and actuators. So far, conventional lasers could not be applied for high precision structuring of semiconductors as they cause thermal melting, cracks, and deposits. Recently, it has been demonstrated that femtosecond laser systems are an ideal tool to overcome these limitations, since thermal and mechanical influences are minimised.

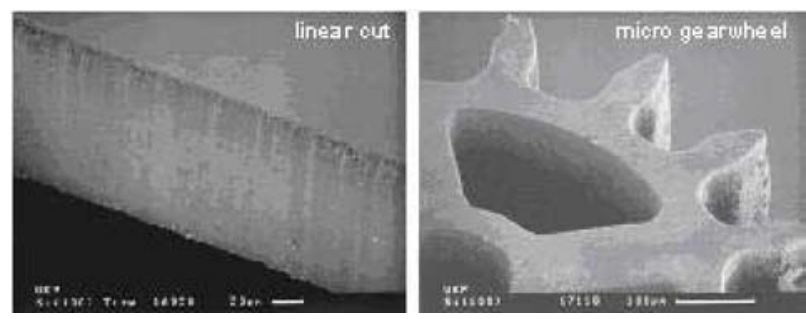

Figure 7.4. Examples of cutting silicon

Cutting of silicon using fs laser pulses shows outstanding high quality results (see Figure 7.4). Since only negligible mechanical stress is induced into the material, this method is very well suited for cutting thin wafers. In contrast to the conventional dicing method, non-linear narrow cuts can be performed with a wear-free tool.

\subsection{Economical considerations}

Investigations on the interaction of ultra-short laser pulses with solid materials have shown that heat diffusion into the surrounding material is reduced with decreasing pulse duration. Therefore, less energy is required and heat affected zones are minimised. Due to the rapid energy deposition the material is heated to very high temperatures, leading to direct evaporation. Since the amount of molten material is negligible the process shows excellent repeatability. The generated structures are characterised through burr-freeness and minimal damage. Besides, the process itself is highly efficient.

Therefore, the highest precision is achieved by applying ultrashort (sub-picosecond) laser pulses. Also the process efficiency is higher compared to "long" pulse ablation due to minimised heat losses. The process quality is enhanced by the fact that there is no interaction between the expanding plasma and the incident laser 
pulse (plasma shielding effect) as light absorption and ablation are sufficiently separated in time.

Although femtosecond lasers offer new and very promising ways of micro-machining almost any solid material, they are not yet introduced into industrial service due to some drawbacks. As the CPA-technique is fairly complex, the system contains much more optical components than conventional lasers. This might influence the stability of operation by changing environmental conditions like temperature, vibrations etc. Up to today, those systems are mainly used for scientific purposes, which necessitates operating the laser by highly trained staff. Regarding industrial operation, such operators are not available. Therefore, industrial service requires much easier operations and less maintenance than most of the typical femtosecond lasers can offer.

A further drawback is the low average power, provided by commercially femtosecond lasers. A typical average power is about $1.5 \mathrm{~W}$, which limits available pulse energy and repetition rate. Typical $<1.5 \mathrm{~mJ}$ and $1 \mathrm{kHz}$. As a result the machining speed is quite low. As many processes do not require very high pulse energies, the speed can be improved by increasing the repetition rate. Therefore, some manufacturers offer systems with up to $5 \mathrm{kHz}$, which reduces the available pulse energy to less than $400 \mu \mathrm{J}$. The laser manufacturers have identified these problems, so the fs-lasers are presently designed to match the requirements of industrial service

In conclusion, fs lasers are presently used for high quality applications, which are not achievable by other means. Due to high investments, low cost applications seem not to be economically machinable by this kind of lasers. Future laser development will increase the process speed by increasing repetition rate as well as average output power. By reducing the costs for the laser system as well, economical machining of several applications will be realised

\subsection{Future developments}

Within the near future alternative approaches based on direct diode pumped laser materials, fiber lasers or parametric amplification will lead to more compact and more reliable systems converting fs lasers into industrial tools. Big effort is also going on to increase the repetition rates of the amplifiers up to $30 \mathrm{kHz}$.

A promising approach is the fully fiber based concept, which provides average power of $1.5 \mathrm{~W}$ and repetition rates up to $10 \mathrm{kHz}$. Main advantage of this concept is the high thermal stability and low electrical consumption. This concept could prove to be very successful, if the life cycle is long enough.

Different gain materials can achieve further increase of average power. Presently, different designs based on Yt:YAG disc lasers are under investigation They can provide higher average powers, but are limited to pulses longer then $700 \mathrm{fs}$.

\section{ACCURACY}

Improvement of accuracy has been a central topic along 50 years of CIRP history as described by Peters [71], Merchant [72], McKeown [73] and many others.

Short pulses have great potential to obtain higher accuracies in dimensional control because of the very small amounts of material that can be removed per pulse, as well because the very small damaged (heat affected) zone at the surface. Another merit of using 'image tools' compared with solid tools (e.g. EDM) is the wide space, available for release of debris. Applications are found in the semiconductor industry where the demand for accuracy follows from the continuing miniaturisation in accordance with Moore's law developed in 1965 [74-76] and in the ultra precision machining following the trend given by Taniguchi in 1983 [77].

In 1965, Gordon Moore, the founder of Fairchild Semiconductor and Intel, observed only six years after the introduction of the commercial planar transistor in 1959 an astounding trend, the number of transistors per chip was doubling every year. In 1975 Moore updated his law distinguishing 3 contributing components:

1) Increasing chip area (15\% each year),

2) Decreasing feature size ( $11 \%$ per year, or $27 \%$ less area). Both factors resulted in $60 \%$ increase of the number transistors per chip;

3) The rest of the improvement was because of better design.

In the first 15 years the chip complexity doubled each year and since 1975 when the design has reached its optimum, the increase was still $60 \%$ per year. When we extrapolate current trends to the year 2010, the minimum feature size will be only $70 \mathrm{~nm}$. This sets the requirements for the future lasers. The feature size depends on four factors; the beam quality should be excellent $\left(M^{2} \approx 1\right)$, the wavelength as short as possible in the $U V$, the $f$ number as small as $\# \approx 1$ and the power density just above the threshold intensity so that only the central part of the beam is used. Currently, feature sizes of $30 \mathrm{~nm}$ have been experimentally demonstrated [78], but it is far from production. Companies are assessing nano photolithography with excimer wavelengths of 193 and $152 \mathrm{~nm}$

In the machine industry Taniguchi published his famous paper in 1983 [77]. From his graphs an increasing accuracy of $10 \%$ per year is found, which is remarkable in balance with the $11 \%$ predicted by Moore. Taniguchi expected in 2010 an ultimate accuracy of $1 \mathrm{~nm}$ by atom, molecule or ion beam machining. He did not consider any laserbeam processing although photons are much finer tool than atoms or ions. Even electron beams are not considered because he says: "it became clear that direct thermal machining using high energy electron beams is not suitable for ultra precision machining because the high energy electrons penetrate the surface layers to depths of many microns or tens of microns (at $50 \mathrm{kV}$ typically $10 \mu \mathrm{m}$ in aluminium). The energy is transferred to the atoms in the form of heat over a relatively large zone of several microns". The reason that photons can perform better is because:

Photons are much smaller than electrons

They are electrical neutral so there are no repulsive forces.

- The optical penetration depth is only $10 \mathrm{~nm}$ for metals

The thermal penetration depth is of the same order.

Taniguchi could not consider this because there was no idea of femtosecond machining at that time. Nevertheless some problems have to be solved before laser micromachining will be applied on industrial scale. Not only the lasers should be more compact and robust but also the reliability in process- and dimensional control is most challenging.

\section{ACKNOWLEDGMENTS}

This paper is a collaborative action of members of the CIRP STC"E" and has grown by valuable discussion in the STC as well by received material from H.K. Tönshoff, D.B. DeBra and G. Spur, A. P. Malshe, Univ. of Arkansas. J. Magee, National Centre for Laser Appl., Univ. of Ireland, M. Knowles University of Cambridge as 
well as Oxford Lasers and N. Preissing, Lambda Physik. Also the support by the Volkswagen Stiftung and the BMBF of the Federal Republic of Germany (chapter four) is gratefully acknowledged.

\section{REFERENCES}

[1] Achenbach, J., 2001. The power of light, National Geographic, October 2001, p 2-31.

[2] Hentschel, M. et al. 2001, Nature 414 p509

[3] Hewett, J. 2002. Time for attosecond consolidation. Optics and Lasers Europe, OLE Jan. 2002, p 30

[4] Chen, $X$. and Liu, X. 1999. Short pulsed laser machining: How short is short enough? Journal of laser applications. Vol. 11, nr 6 p268-272.

[5] Bosman J. 2002, Laser engraving processes. PhD thesis, University of Twente (in press)

[6] Semak, V., 2001, Laser drilling: from milli to femto, Laser solutions course, ICALEO 2001, Jacksonville, 18 October, $p$ 1-9.

[7] Ohmura, E and I. Miyamoto. 1998. Molecular dynamics simulation on laser ablation of metals and silicon. Int. J. of Japan Soc. Prec. Eng. Vol 34 No 4, p 248-253.

[8] Ishizaka, Y, K. Watanabe, I. Fukumoto, E. Ohmura and I. Miyamoto. 1998. Three-dimensional molecular dynamics simulation on laser materials processing of silicon. Proc. ICALEO98, p A55 -63.

[9] Ohmura, E, I. Fukumoto and I. Miyamoto. 1998. Molecular dynamics simulation on laser ablation and thermal shock phenomena. Proc. ICALEO 1998, p A45 -54

[10] Ohmura, E and I. Fukumoto. 1996. Study on fusingand evaporating process of fcc metal due to laser irradiation using molecular dynamics. Int. J. of Japan Soc. Prec. Eng. Vol 30, No 1, p 47-48.

[11] McClung, F J, Hellwarth R W 1963 Characteristics of Giant Optical Pulsations from Ruby Proc. IEEE 5146.

[12] Mocker, H.W., and R.J. Collins, 1965, Mode competition and self-locking effects in a Q-switched ruby laser. Applied Physics Letters no 7, p.270

[13] Krausz, F, Brabec T, Spielmann, C 1991 Selfstarting passive mode locking Opt. Letters 16235

[14] DeMaria, A J, Stetser D A, Heynau, H 1966 Self mode-locking of lasers with saturable absorbers Applied Physics Letters 8174

[15] Spence D E, Kean, P N, Sibbet, W 1991 60-fsec pulse generation from a self-mode-locked Ti:sapphire laser Optics Letters 1642.

[16] Guillot, D., 1998, Microlasers. Photonics Spectra. Feb. 1998. P 143-146.

[17] Kovalenko, V.S. Laser technology, Vyscha Schola, Kiev, 1989, $280 p$

[18] Ogura, G., J. Angell and D. Wall: Applications test potential of laser micromachining. Laser Focus World, June 1998, 117-123.

[19] Weck, M., Schröder, H.B., 1993, Thermal Energy from Machining Process - A dominating factor on form accuracy in ultra- and high precision turning, Proceedings of the 8th ASPE Annual Meeting, Nov. 7-12th 1993, Seattle, Washington, USA, 170-173.

[20] Kruth, J.-P., Tönshoff, H. K., Klocke, F., 1998, Surface and Sub-Surface Quality in Material Removal Processes for Tool Making, Int. Symp. Electromachining ISEM XII 1998, Aachen,
Germany, in: VDI Berichte, F. Klocke, J.-P. Kruth (eds.), 1405:33-64.

[21] Kostrykin, V., M. Niessen, J. Jandeleit, W. Schulz, E.W. Kreutz, and R. Poprawe, 1998, Picosecond laser pulses induced heat and mass transfer. Proc. SPIE Vol. 3343, p. 971-982.

[22] Klimentov, S.M., Garnov, S.V., Kononenko, T.V., Konov, V.I., Pivovarov, P.A., Dausinger, F., 1999, High rate deep channel ablative formation by picosecond-nanosecond combined laser pulses, Applied Physics A 69:633-636.

[23] Stewen, C., Contag, K., Larionov, M., Giesen, A., Hügel, $H_{\text {., }} 2000$, A 1-kW Thin Disc Laser, IEEE JSTQE 6(4):650-658.

[24] Brunner, F., Spühler, G.J., Aus der Au, J., Krainer, L., Morier-Genoud, F., Paschotta, R., Weiss, S., Harder, C., Lagatsky, A.A., Abdolvand, A., Kuleshov, N.V., Keller, U., 2000, Diode-pumped femtosecond $\mathrm{Yb}: \mathrm{KGd}(\mathrm{WO} 4) 2$ laser with $1.1 \mathrm{~W}$ average power, Opt. letters 25(15):1119-1121.

[25] Du, K., Wu, L., Xu J., Giesekus, J., Loosen, P., Poprawe, R., 1998, Partially end-pumped Nd:YAG slab laser with hybrid resonator, Optics Letters 23(5):370-372.

[26] Schmidt, G., Hoffmann, H.D., Bonati, G., Wester, R., Loosen, P., Poprawe, R., 1999, A New Diode Pumped Multi kW Solid State Laser-Modelling of the Performance in Comparison with Experimental Results, Proceedings Photonics West 99.

[27] Koch, R., Schröder, T., Stamm, U., Zschocke, W., Basting, D., 1998, High Average Power, High Pulse Repetition Frequency Diode Pumped UV SolidState Laser System, Glasgow (UK), Proc. Cleo Europe 98, paper CWJ5.

[28] Tönshoff, H. K., Mommsen, J., 1992, Process of generating three-dimensional microstructures with excimer lasers, Proc. ECLAT92, Göttingen.

[29] Hellrung, D., Gillner, A., Poprawe, R., 1997, Laser beam removal of micro-structures with $\mathrm{Nd}$ :YAG lasers, Proc. Lasers in Material Processing Laser'97, Munich, SPIE 3097:267-273.

[30] Spur, G. 2001: Industrial cleaning technologies for hard surfaces: dry ice blasting and laser. Proc. $40^{\text {th }}$ Int. detergency conf. IDC'01, p 156-165.

[31] Hoving, W. Philips, CFT. Private communications.

[32] Lee, J.M., K.G. Watkins and W.M. Steen, 2001, Surface cleaning of silicon wafer by laser sparking, J. Laser Appl., Vol 13, 4, p. 154-158.

[33] Ready, J.F., 1971, Effects of high power laser radiation (Academic, New York), p.213.

[34] Kidder, R.E., 1968, Nucl. Fusion, 8, 3.

[35] Geiger, M., M. Kleiner, R. Eckstein, N. Tiesler, U. Engel, Microforming, Annals of the CIRP Vol. $50 / 2 / 2001$, p. $445-462$.

[36] Hoving, W., 2001 Laser fine adjustment, Proc. ICALEO 2001.

[37] Otsu, M., T. Wada and K. Osakada, 2001, Micro bending of thin spring by laser forming and spark forming, Annals of the CIRP, Vol. 50/1, p 141-144.

[38] Meijer, J. In J.A. McGeough 2002 Micromachining materials Marcel Dekker, NY, p203- 237.

[39] Galantucci, L.M., 1998, Excimer laser cutting: Experimental characterization and 3D numerical modelling for polyester resins, Annals of the CIRP Vol. 47/1/1998, p 141-144.

[40] Elliot, D.J. Ultraviolet laser technology and applications. Academic Press, NY 1995 
[41] Basting, D. 2001, Excimer laser technology: Laser sources, optics, systems and applications. Lambda Physik AG, Göttingen (D)

[42] Hind, A., 2001, Spectrophotometry Takes measure of deep UV Lithography, Photonics Spectra Dec 2001, p 82-86.

[43] Burnett, J.H, Z.H. Levine, E.L. Shirley, 2001, Hidden in plain sight: Can lithographers design out the intrinsic birefringence of calcium fluoride, or must they find a new material solution for $157 \mathrm{~nm}$ lithography, Photonics Spectra, Dec 2001, p 88-92.

[44]www.cee.hw.ac.uk/microengineering/microsystems/u v-ligal.

[45] MacGeough,J.A., M.C. Leu, K.P. Rajurkar, A.K.M. De Silva and $Q$. Liu, 2001, Electroforming process and application to micro/macro manufacturing, CIRP Annals, Volume 50/2/2001, pp.499-514.

[46] Ready, J.F. 2001, LIA Handbook of Laser Materials Processing. Magnolia Publ. Inc p 491

[47] Bachmann, F.G. 1990, Industrial laser applications, Appl. Surface Science 46, p. $254-263$.

[48] Riccardi, G., M. Cantello, F. Mariotti, P. Giacosa, 1998. Micromachining with excimer laser, Annals of the CIRP, Vol. 47/1/1998, p 145-148

[49] Lasers are Diamond's best friend. Photonics Spectra. June 1992. p.40

[50] Windholz, R., and P. Molian, 1997, Nanosecond pulsed excimer laser machining of CVD diamond and HOPG graphite, J. Mater. Sci. 32, p. 42954301.

[51] Shirk, M.D., and P.A. Molian, 1998, Ultrashort laser ablation of diamond, $\mathrm{J}$. of Laser Applications. Vol 10,2 , p. $64-70$

[52] Lotze, R. J. Birkel, K. Wissenbach. 1999. Entlacken mit Laserstrahlung. Neue industrielle Anwendungen. JOT Journal für Oberflächentechnik 1999/8.

[53] Klein, S. T. Stratoudaki, V. Zafiropoulos, J. Hildenhagen, K. Dickmann, Th. Lehmkuhl, 1999 Laser induced breakdown spectroscopy for on line laser cleaning of sandstone and stained glasses. Appl. Phys. A69 p 441-444

[54] www.art-innovation.n|

[55] A. Schoonderbeek, C.A. Biesheuvel, R.M. Hofstra, K-J. Boller, J. Meijer, 2002, "High speed drilling of metals with a long pulse $\mathrm{XeCl}$ excimer laser", Proc. SPIE 4760 High-Power Laser Ablation IV.

[56] Fotakis, C. 1998 in Handbook of the EuroLaser Academy, Chapman \& Hall, London, Vol. 1, p 227 265.

[57] Burgess, D.S., 2001, Laser ablation generates nanoparticles, Photonics Spectra, July '01, p. 26-29

[58] Masuzawa, T, J. Olde Benneker, J.J.C. Eindhoven, 2000, A new Method for three dimensional excimer laser micromachining by Hole area modulation (HAM), Annals of the CIRP Vol. 49/1, p 139-142.

[59] Illy, E.K. and J.A. Piper. Micromachining cuts cost for Copper Vapor Lasers, Photonics Spectra March 1998, 106-111.

[60] Kovalenko, V., M. Anyakin, Y. Uno, 2000, Modeling and Optimization of Laser Semiconductor Cutting, Proceedings of the ICALEO, Vol.90, Laser Microfabrication, p.D82-D92

[61] Allen, D, H. Almond and P. Logan. A technical comparison of micro-electrodischarge machining, micro drilling and copper vapour laser machining for the fabrication of ink jet nozzles. Proc. SPIE Vol. 4019 (2000), p 531-540.

[62] S. Elmes et al. 2001. Laser machining of micro reservoir pins for gene analysis and high throughput screening. ICALEO Laser Micro fabrication Conf. M303, ISBN 0-912035-73-0

[63] Allen, D.M., H.J.A. Almond, J.S. Bhogal, A.A. Green, P. Logan, X.X. Huang. Typical metrology of Micro hole arrays made in stainless steel foils by two stage EDM. Annals of the CIRP Vol.48/1/1999, pp127-130.

[64] Almond, H, J. Bhogal and D.M. Allen. A positional accuracy study of a micro EDM machine. Proceedings of SPIE, 3680, p. 1113-1124. 1999

[65] Masuzawa, T., 2000, State of the art of micromachining. Annals of the CIRP Vol. 49/2/2000, pp $473-488$

[66] Kearsley, A. and K. Errey. Powerful pulses focus on industry's material needs. Opto \& Laser Europe. $\mathrm{Nr}$ 26

[67] Nolte, S. et al., 1997, Ablation of metals by ultrashort laser pulses. J. Opt. Soc. Am B; Vol. 14, No. 10, p.2716-2722

[68] Strickland, D. and G. Mourou, 1985, Compression of amplified chirped optical pulses. Opt. Comm.. 56 , 219.

[69] Lubatschowski, H. et al., 2002. Ultrafast Laser Pulses for Medical Applications. Proceedings of SPIE, LA 4633-07, (in press)

[70] Momma, C., U. Knoop, S. Nolte, 1999, Laser cutting of slotted tube coronary stents. State of the art and future developments; Biomedical research, p.39-44

[71] Peters, J., et. al. Contribution of CIRP to the development of metrology and surface quality evaluation during the last fifty years, Annals of the CIRP Vol. 50/2/2001, pp 471 - 489.

[72] Merchant, M.E., 1971, Delphi forecast of future production engineering, Annals of the CIRP, 20/2/1971, p. 205-213.

[73] Mckeown, P.A., 1987. The role of precision engineering in manufacturing of the future. Annals of the CIRP, 36/2/1987, p 495-502.

[74] Moore, G.E., 1965, Cramming more components onto integrated circuits, Electronics 38, p 114-117

[75] Moore, G.E., 1975, Progress digital integrated electronics, IEDM Techn. Digest, Washington. p11-13.

[76] The national Technology Roadmap for Semiconductors, 1994, (Semiconductor Industry Association San Jose, Calif.).

[77] Taniguchi, N. 1983. Current status in, and future trends of, ultra precision machining and ultra fine materials processing. Annals of the CIRP Vol. 32/2/1983 p573-580.

[78] Corbett, J., P.A. McKeown, G.N. Peggs, R. Whatmore, 2000, Nanotechnology: International developments and emerging products. Annals of the CIRP, Vol. $49 / 2 / 2000$, p. 523-545 